University of Rhode Island

DigitalCommons@URI

Open Access Dissertations

2017

\title{
Testing the Effectiveness of Brief Psychoeducation to Improve Parent Problem Recognition
}

Caroline M. Segal

University of Rhode Island, caroline.m.segal@gmail.com

Follow this and additional works at: https://digitalcommons.uri.edu/oa_diss

\section{Recommended Citation}

Segal, Caroline M., "Testing the Effectiveness of Brief Psychoeducation to Improve Parent Problem Recognition" (2017). Open Access Dissertations. Paper 653.

https://digitalcommons.uri.edu/oa_diss/653

This Dissertation is brought to you for free and open access by DigitalCommons@URI. It has been accepted for inclusion in Open Access Dissertations by an authorized administrator of DigitalCommons@URI. For more information, please contact digitalcommons-group@uri.edu. 
TESTING THE EFFECTIVENESS OF BRIEF PSYCHOEDUCATION TO IMPROVE PARENT PROBLEM RECOGNITION

BY CAROLINE M. SEGAL

\begin{abstract}
A DISSERTATION SUBMITTED IN PARTIAL FULFILLMENT OF THE REQUIREMENTS FOR THE DEGREE OF DOCTOR OF PHILOSOPHY
\end{abstract}

IN

PSYCHOLOGY

UNIVERSITY OF RHODE ISLAND

2017 
DOCTOR OF PHILOSOPHY DISSERTATION

OF

CAROLINE M. SEGAL

APPROVED:

Dissertation Committee:

Major Professor: Ellen Flannery-Schroeder

Andrea Paiva

Leslie Mahler

Nasser H. Zawia

DEAN OF THE GRADUATE SCHOOL

UNIVERSITY OF RHODE ISLAND 


\begin{abstract}
A significant discrepancy exists between the rate of mental health problems in children and adolescents and their engagement in mental health services. A major contributor to this problem is poor mental health literacy among parents. Parents are typically responsible for identifying mental health issues in their children, but studies show that they struggle with problem recognition. The current study is the first randomized controlled trial to assess the effectiveness of an intervention to increase parents' recognition skills of children's mental health problems. Participants included 298 participants recruited from community and online settings. Participants ranged in age from 24 to 58 and had at least one child between ages three and 17. Parents who were randomly assigned to the intervention group viewed a pamphlet designed for the current study that provided psychoeducation about problem recognition. Parents in the control group did not view the pamphlet. All parents read three vignettes that described a child with an anxiety disorder, ADHD, and no clinical diagnosis, then completed measures of problem recognition, problem severity, and perceived need for services. Parents also answered questions about their own experiences with mental health issues. Findings revealed that the intervention did not improve problem recognition or increase perceived need for services. However, problem recognition, problem severity, and perceived need for services were rated higher among parents with a personal or familial history of mental health problems, suggesting that mental health experience increases mental health literacy. Additionally, more parents, particularly women, recognized symptoms of anxiety than symptoms of ADHD, which contrasts findings from previous studies. Personal history of anxiety was
\end{abstract}


particularly high among our study sample, which may explain the disproportionately high rate of anxiety recognition. Together, these findings suggest that problem recognition is influenced by knowledge of and experience with mental health issues. Due to the brevity of the pamphlet, the dose of the intervention may have been too low to effect observable change in problem recognition. Future research is warranted to continue exploring the impact of other interventions to increase parents' problem recognition skills. 


\section{Acknowledgements}

I would like to extend my utmost gratitude to my major professor, Dr. Ellen Flannery-Schroeder, for her expert guidance and tireless support over the years. She has exhibited tremendous patience, warmth, and optimism, and I consider her to be a cherished and, hopefully, lifelong friend. I would also like to thank my dissertation committee, Dr. Andrea Paiva, Dr. Leslie Mahler, and Dr. Sue Adams, for their invaluable input into the development of this research. Dr. Paiva, in addition to guiding me through my every statistical question, contributed substantially to the recruitment process; without her, I might still be scrambling to collect data. A hearty thank you goes, as well, to Roni Leiderman, the Director of Research and Evaluation at the Mailman Segal Center for Human Development, Noelle Millholt, Co-Founder and COO of Speakaboos, Susan Orban, Coordinator of the Washington County Coalition for Children, Lev Sviridov, Director of the Macaulay Honors College at Hunter College, and Ailene Altman, Principal of the Park Slope Education Complex at M.S. 88, for helping me to recruit within their respective institutions. I would like to recognize the efforts of my wonderful parents, Monica and Rick Segal, who helped me identify recruitment sources and have stood by me through all the ups and downs of this doctoral degree. My mother has read and edited every academic paper I have produced since kindergarten, and I am grateful for her keen eye and attention to detail. Lastly, I am endlessly appreciative of (and constantly awed by) the unconditional love and support I receive from my husband, Scott Weiner, each and every day. I would not be where I am today if not for his unwavering devotion and confidence that I would reach the finish line. 


\section{Table of Contents}

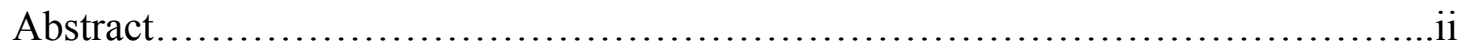

Acknowledgements....................................................

Table of Contents.............................................................

List of Tables......................................................... vi

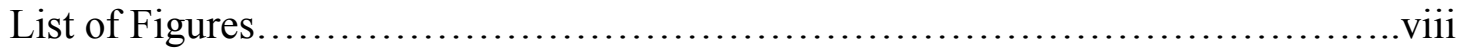

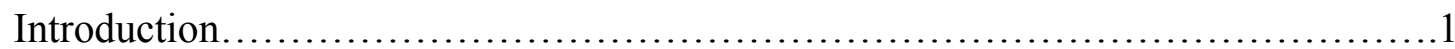

Method.................................................................... 14

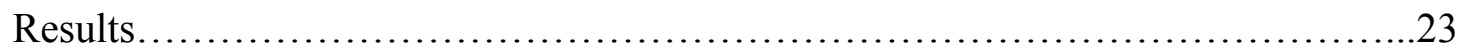

Discussion................................................................ 41

Appendices.............................................................. 71

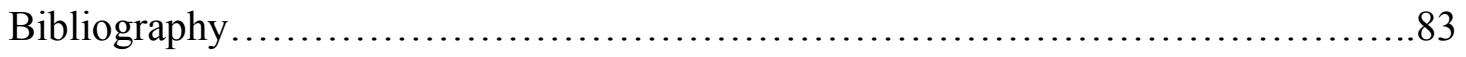




\section{List of Tables}

Table 1. Descriptive Statistics for Problem Severity................................59

Table 2. Demographic Characteristics of Participants...............................60

Table 3. Rate of Problem Recognition in the Anxiety Vignette.......................62

Table 4. Rate of Problem Recognition in the ADHD Vignette.......................62

Table 5. Rate of Problem Recognition in the TDC Vignette.........................62

Table 6. Logistic Regression Predicting Problem Recognition in the Anxiety

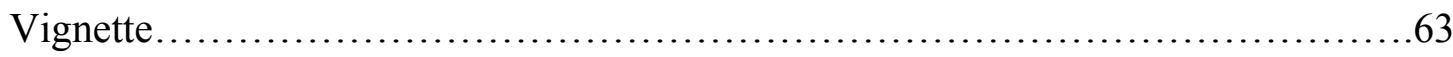

Table 7. Logistic Regression Predicting Problem Recognition in the ADHD

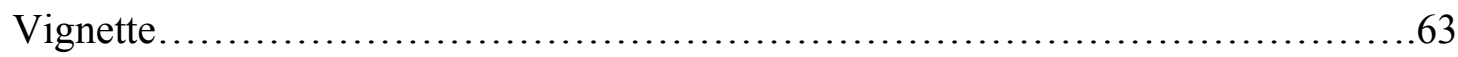

Table 8. Logistic Regression Predicting Problem Recognition in the TDC

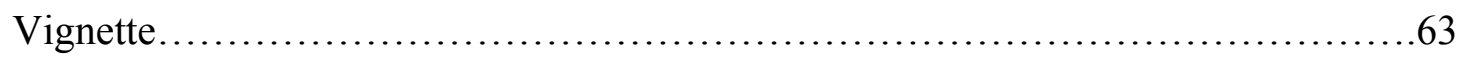

Table 9. Rate of Perceived Need for Services in the Anxiety Vignette................64

Table 10. Rate of Perceived Need for Services in the ADHD Vignette................64

Table 11. Rate of Perceived Need for Services in the TDC Vignette..................64

Table 12. Logistic Regression Predicting Perceived Need for Services in the Anxiety

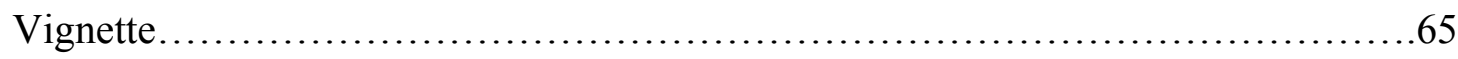

Table 13. Logistic Regression Predicting Perceived Need for Services in the ADHD

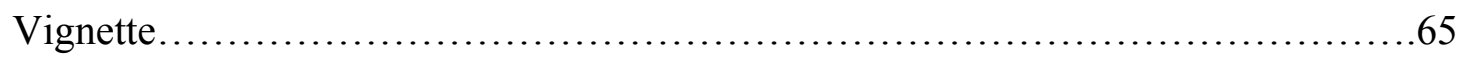

Table 14. Logistic Regression Predicting Perceived Need for Services in the TDC

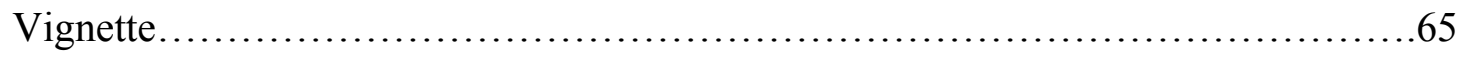

Table 15. Service Recommendations by Vignette.................................66 
Table 16. Cross-Tabulation of Problem Recognition and Perceived Need for Services

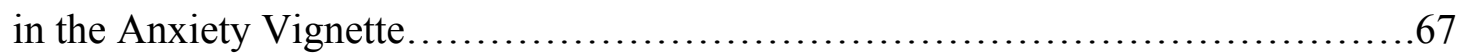

Table 17. Cross-Tabulation of Problem Recognition and Perceived Need for Services

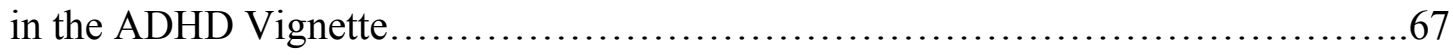

Table 18. Sources Parents Use to Learn about Child Rearing and Child

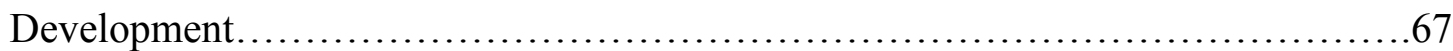




\section{List of Figures}

Figure 1. Flow Diagram of Participants....................................68

Figure 2. Predictors of Problem Severity in the ADHD Vignette..................69

Figure 3. Predictors of Problem Severity in the TDC Vignette..................... 70 


\section{Introduction}

Various studies report that $10-23 \%$ of children and adolescents experience emotional and/or behavioral difficulties (Burns et al., 1995; Costello et al., 2003; Meltzer et al., 2003; Merikangas et al., 2010; Ravens-Sieberer et al., 2008; Waddell et al., 2002; Guo et al., 2014). Despite the high prevalence of mental health issues among this population, only $5-10 \%$ of children with mental health issues receive treatment (Koot \& Verhulst, 1992; Shanley, 2008; Bussing et al., 2003; Guo et al., 2014). Even among high-risk populations, the rate of treatment is alarmingly low, hovering around 25\% (Girio-Herrera et al., 2013; Lindsey et al., 2010; Bussing et al., 2003).

Without treatment, children experiencing mental health problems are at increased risk for adverse outcomes including academic problems, substance use issues, interpersonal difficulties, and persistence or escalation of psychological impairment (Briggs-Gowan \& Carter, 2008; Kessler et al., 2005; Patel et al., 2007). Untreated mental illness also bears significant social and economic costs to families and to communities (Snell et al., 2013; Scott et al., 2001; Greenberg et al., 1999). Therefore, efforts are needed to improve service utilization rates for mental health issues for children and adolescents.

The process of acquiring mental health services has been posited to follow a linear series of stages: 1) problem recognition, 2) decision to seek help, and 3) service selection (Goldsmith et al., 1988). Multiple studies have demonstrated that each stage in this model predicts the next (Thurston et al., 2015; Brown et al., 2014; Godoy et al., 2014; Teagle, 2002; Girio-Herrera et al., 2013). The third stage of this model, service selection, has received the most attention in the literature, as many studies highlight 
logistical barriers (e.g., cost of services, need for childcare, need for transportation), systemic barriers (e.g., wait lists, insurance complications, and eligibility policies), and social perception barriers (e.g., perceived stigma, mistrust of providers, poor understanding of services) to treatment (Sayal et al., 2015; Srebnik et al., 1996; Bussing et al., 2003; Boulter \& Rickwood, 2013; Lindsey et al., 2013; Brown et al., 2014).

However, the first stage, problem recognition, has been largely overlooked. Problem recognition is used here to signify perception or awareness that a child has a significant behavioral or emotional problem (see Teagle, 2002). If the stages of the model are, in fact, linear, then children are theoretically unable to progress towards service use without successful problem recognition. Therefore, efforts are needed to better understand how children's mental health problems are identified to improve engagement with mental health services for children whose problems are yet unidentified.

Extant research suggests that parents play an important role in identification of children's psychological issues and, ultimately, pursuit of formal intervention. Parents are often the first to recognize problematic symptoms in their child, usually before teachers, doctors, or the child him or herself (Boulter \& Rickwood, 2013; Brown et al., 2014; Hall \& Bierman, 2015; Sourander et al., 2004). In cases where the child is the first to identify a behavioral, emotional, or learning difficulty, he or she often turns to a parent first for emotional support (Boulter \& Rickwood, 2013; Lindsey et al., 2013). In addition to problem recognition, parents typically bear the responsibility of identifying a need for intervention for their child, as well as seeking out the 
appropriate source of help. In most states, children under the age of 18 cannot receive health-related services without parental consent (Department of Health and Human Services, 2009; Committee on Bioethics, 1995). Therefore, parents are a key population to study the process of problem recognition and pursuit of intervention for children with behavioral or emotional difficulties.

Unfortunately, rates of parents' problem recognition are low (Godoy et al., 2014; Srebnik et al., 1996; Simpson, 1988). Consistently, fewer than half of parents whose children score positively on psychological diagnostic screens acknowledge problem behavior (Oh et al., 2015, Zwaanswijk et al., 2006; Girio-Herrera, et al., 2013). Several studies show parental recognition rates below $20 \%$ (Teagle, 2002; Zahner, 1992; Verhulst \& Van der Ende, 1997).

Studies suggest that parents may struggle with problem recognition due to a tendency to normalize problematic behavior or remain "in denial" about their child's condition (Brown et al., 2014; Brestan et al., 2003). In a study of children with developmental delays, parents vacillated between feelings of concern and beliefs that the delays were transient, often convincing themselves that the problem would resolve itself (Marshall et al., 2016). Some parents cope with children's mental illness by avoiding or ignoring the problem altogether (e.g., Kolvenbach et al., 2016; Moses, 2011; Woodman \& Hauer-Cram, 2013).

Problem recognition (Godoy et al., 2014; Teagle, 2002; Bussing et al., 2003; Boulter \& Rickwood, 2013) and service use (Ford et al., 2008; Zwanswiijk et al., 2003; Koot \& Verhulst, 1992) have been shown to increase as parents' perception of symptom severity and the negative impact of problem behaviors on family functioning 
increase. This finding is consistent across both internalizing (Breland et al., 2014) and externalizing (Sayal et al., 2010) conditions. However, it seems that parents experience a threshold beyond which problem behaviors are sufficiently visible, excessive, and impactful to cause concern. Brown and colleagues (2014) demonstrated that many parents delayed help-seeking due to beliefs that their children's problems were not severe enough to warrant services. The process of normalization may downshift parents' recognition of the severity of the problem.

This tendency to normalize behaviors may reflect a process of resolving cognitive dissonance (Festinger, 1957). Parents often respond to problematic child behavior by shifting their attitudinal threshold for "problematic" rather than acting to change the behavior. For example, Glatz and colleagues (2012) found that parents who initially strongly opposed underage alcohol use were more likely to flex their attitudes upon finding their children intoxicated than to increase parental control.

In countries like the United States, where individual success is so highly valued, recognizing a problem may be perceived as admission of a child's imperfections, which may in turn threaten parents' self-esteem (Willinger et al., 2011). For example, Thomson and colleagues (2014) found that parents of children with anorexia nervosa tended to reframe weight loss as normal or even positive to allay feelings of guilt that they could not manage the problem themselves. In a focus group of Black parents of children with mental health issues, caregivers frequently identified blaming themselves for their children's problems (Lindsey et al., 2013). Parents who overestimate their child's functioning have been shown to experience lower levels of 
parenting stress (Willinger et al., 2011); thus, normalizing rather than addressing problematic behaviors may help to preserve parenting self-efficacy.

The struggle of addressing children's problem behaviors continues even when a mental health problem has been identified. Mental health screening is increasingly performed in classrooms and pediatricians' offices, with promising findings regarding rates of problem detection (Essex et al., 2009; Eklund et al., 2009; Hacker et al., 2006; Hacker et al., 2014). However, identification of a problem does not seem to translate to parents' awareness and acceptance of the need for treatment. Bussing and colleagues (2003) found that $66 \%$ of parents of children identified as high risk for attention-deficit/hyperactivity disorder (ADHD) did not believe their child needed treatment, with $36 \%$ reporting that the problem was likely to improve on its own. Girio-Herrera and colleagues (2013) reported that less than one-fifth of parents of atrisk children pursued an initial mental health evaluation for their child, and Kataoka and colleagues (2007) found that one third of parents do not follow through after receiving a referral.

Several studies point to mistrust of mental health professionals and negative attitudes and expectations of psychological practices as explanatory factors of low rates of help-seeking (Lindsey et al., 2013; Molock et al., 2007; Thompson et al., 2004). Brown and colleagues (2014) found that parents commonly reported fears that their child would be stigmatized, medicated, or institutionalized if they pursued mental health treatment, which deterred them from following through with referrals.

Instead of pursuing specialty mental healthcare, parents more often turn to school-based or medical services for support (MacNaughton \& Rodrigue, 2001; Girio- 
Herrera et al., 2013; Bussing et al., 1998; Brown et al., 2014; Sayal et al., 2015; Sourander et al., 2004). Unfortunately, fewer than one third of teachers believe they have the knowledge and skills required to adequately meet the needs of students with mental health issues (Reinke et al., 2011), and pediatricians and general practitioners evidence poor mental health problem recognition skills themselves (Zwaanswijk et al., 2003; Glascoe \& Marks, 2011). In fact, many parents have reported that their child's pediatrician also normalized problematic behaviors, which led parents to experience further confusion regarding problem recognition (Brown et al., 2014; Sayal, 2006; Godoy \& Carter, 2013; Clarke, 2012).

The pervasive tendency to normalize, "explain away," or miss the signs of problematic behavior leads to delays in treatment acquisition, which puts children in need at further risk for adverse outcomes. Studies suggest that the delay between symptom onset and treatment initiation can range from six to 23 years (Comer, 2015; Wang et al., 2005). Elucidating successful strategies to increase parents' problem recognition skills is expected to reduce this gap and improve child outcomes.

\section{Predictors of Parental Problem Recognition}

To develop appropriate interventions to increase identification of children's mental health problems, consideration of known predictors of parental problem recognition is warranted. Several predictors that have been consistently identified in the literature include parents' mental health experience, gender, and problem type. Each predictor will be addressed separately in the following sections.

Mental health experience. Problem recognition falls within the scope of mental health literacy, an umbrella term for level of knowledge about prevention, 
recognition, and treatment of mental health disorders (Kutcher et al., 2016). Parents tend to exhibit poor mental health literacy at baseline (Ryan et al., 2015; Coffman \& Norton, 2010; Collier et al., 2012). However, personal experience of mental health issues appears to increase mental health literacy. Mendenhall and Frauenholtz (2015) found that parents exhibited greater knowledge about mood disorders if they had a personal history of mental health issues and/or treatment. Similarly, in an online study of adults presented with anxiety vignettes, those with a personal history of mental health treatment exhibited small but significant increases in mental health literacy (Schofield et al., 2016).

Few studies have explored the relationship between parents' mental health literacy and problem recognition in children, but one of the strongest predictors of children's mental health service use is parents' personal history of help-seeking (Oh et al., 2015; Gronholm et al., 2015). This finding suggests that parents who are familiar with mental health services may be more likely to identify problem behaviors and seek services for their children.

Gender differences. Many studies have found problem recognition rates to differ by child gender. In general, problem behaviors are more often identified and addressed in boys than girls (Sayal et al., 2015; Haines et al., 2002). This effect is particularly pronounced for externalizing disorders, such as ADHD (CDC, 2013; Pihlakoski et al., 2006; Zwaanswijk et al., 2003; Bussing et al., 2003; Sayal et al., 2015; Sayal et al., 2010).

While diagnostic discrepancies in externalizing disorders may reflect genuine differences in prevalence of mental health issues by gender, they may also point to 
biases in perception. Quinn and Wigal (2004) found that the majority of the general public believes that ADHD is more prevalent among boys than girls. Studies also show a tendency to overattribute aggression, an externalizing symptom, to boys (see Pellegrini, 2011). Even professionals who work with children are susceptible to overattend to externalizing symptoms in boys. In a study investigating teachers' problem recognition skills, teachers exhibited more accurate problem recognition of a vignette depicting a child with externalizing symptoms when the character was male compared to an equivalent vignette with a female character (Loades \& Mastroyannopoulou, 2010). Similarly, general practitioners expressed greater concern about male vignette characters than female exhibiting identical externalizing symptoms (Jacobs \& Loades, 2016).

Considering these findings, parents, especially those with low mental health literacy, may be primed to attend more strongly to symptoms of ADHD in boys than girls. However, more research is needed to identify the extent to which gender discrepancies across diagnostic categories are skewed by gender schemata.

Problem type. Rates of recognition have been shown to be higher for externalizing disorders than for internalizing disorders (Teagle, 2002; Sourander et al., 2006; Pihlakoski et al., 2006; Abera et al., 2015). Lyneham and Rapee (2007) found that just over half of mothers in Australia expressed concern when their child exhibited purely internalizing symptoms, compared to $80 \%$ of mothers with children exhibiting externalizing symptoms. When using vignettes to elicit parents' problem recognition skills, Thurston and colleagues (2015) found that 52\% recognized internalizing symptoms as problematic and 61\% identified externalizing symptoms as 
problematic. Externalizing disorders are likely easier to recognize than internalizing disorders due to greater visibility of symptoms (Cantwell et al., 1997). Externalizing symptomatology in children has been shown to predict not only parental problem recognition but also parents' perceived need for services and actual service use (Sayal, 2006; Pihlakoski et al., 2004).

When considering recognition rates by problem type, it is important to consider cultural differences. Although Black children are notably under-diagnosed for mental health problems (Bussing et al., 2003; Zwaanswijk et al., 2003), externalizing symptomatology tends to be over-identified in this population, especially by teachers (Lawson et al., 2017; Lau et al., 2004; Youngstrom et al., 2000). Additionally, Guo and colleagues (2014) found that the presence of externalizing symptoms is more often identified in Latino/Hispanic children than Asian American children, and internalizing symptoms are more commonly recognized in Asian American children than Latino/Hispanic children (Guo et al., 2014). Of all racial and ethnic groups, non-Hispanic Whites are most likely to receive services specifically for internalizing disorders, whereas service utilization rates appear more equivalent across ethnic and racial groups for externalizing disorders (Gudiño et al., 2009; Alexandre et al., 2009). Differences in problem recognition and service use by ethnic and racial category may be explained in part by cultural differences in symptom presentation, but racial/ethnic bias and dependence on stereotypes likely influences problem perception as well (Stein et al., 2010; Lawson et al., 2017; Kolvenbach et al., 2016). 


\section{Intervening to Improve Problem Recognition}

Despite the availability of evidence suggesting that parents exhibit poor problem recognition skills, few empirical studies to date have tested attempts to improve these skills. Umpierre and colleagues (2015) found preliminary support for a children's mental health literacy campaign directed at Latino parents, and Tanzanian parents expressed positive feelings about receiving psychoeducation to detect autism (Harrison et al., 2016). However, both of these interventions required in-person attendance, which is both costly and self-selective. Considering the aforementioned tendency towards denial, it is reasonable to presume that the target demographic for these interventions is unlikely to engage in a workshop or seminar specifically addressing mental health issues. The current study explored the effectiveness of written psychoeducational materials as a low cost, low threat mechanism to increase mental health problem recognition skills among parents.

The use of short written materials to increase mental health literacy has elicited mixed findings regarding effectiveness. Rees and colleagues (2014) developed a short text to increase awareness of intrusive thoughts associated with obsessive compulsive disorder. In a randomized controlled trial, they found that participants who read this text demonstrated significant improvements in their appraisals of intrusive thoughts compared to participants reading a neutral text. Similarly, Dueweke and Bridges (2017) found that Latino immigrants demonstrated increased knowledge of suicide after reading a brief pamphlet compared to controls. However, reading the pamphlet did not influence participants' attitudes towards help-seeking or feelings of stigma about suicidality. Similarly, Hay and colleagues (2007) found that young women who 
exhibited signs of disordered eating were no more likely to recognize these behaviors as problematic if they read psychoeducational materials about eating disorders.

To date, there have been no studies assessing the use of written psychoeducational materials to improve parents' problem recognition skills. This study represents the first randomized controlled trial to explore the effectiveness of written information to increase parents' ability to recognize children's mental health problems. The author designed a pamphlet that encouraged parents to consider the frequency, persistence, and impact on functioning of their child's behavioral patterns as steps towards problem recognition. The goal of the pamphlet was to prime parents with the knowledge, language, and perspective on children's mental health to recognize concerns and be informed self-advocates.

To assess the effect of the pamphlet and other predictors on parental problem recognition, perceived problem severity, and perceived need for services, participants read vignettes about a child with anxiety, a child with ADHD, and a typicallydeveloping child, and were asked to identify whether each child exhibits problem behavior. Vignettes have been effectively used in previous mental health research to explore mental health literacy and problem recognition (e.g., Greenhalgh \& Shanley, 2016; Chambers et al., 2015; Coles et al., 2014). In an examination of the feasibility of vignettes to elicit parents' attitudes about mental health, Lapatin and colleagues (2012) found that parents were able to read and respond to vignettes without difficulty and generally rated the experience favorably. The vignettes used in the current study were constructed by Thurston and colleagues (2015) and used in a previous study to analyze 
predictors of parents' problem recognition skills. To that end, the following hypotheses were tested:

1a) Participants who receive a brief psychoeducational intervention will be more likely to recognize problem behaviors in the anxiety and ADHD vignettes than participants who do not receive the intervention. 1b) Participants will be more likely to recognize problem behaviors in the anxiety and ADHD vignettes if they or their children have had prior experience with mental illness. 1c) Participants will be more likely to recognize problem behaviors in the ADHD vignette if it features a boy rather than a girl.

2a) Participants who receive the intervention will report greater problem severity in the anxiety and ADHD vignettes than participants who do not receive the intervention. 2b) Participants will report greater problem severity in the anxiety and ADHD vignettes if they or their children have had prior experience with mental illness. 2c) Participants will report greater problem severity in the ADHD vignette if it features a boy rather than a girl.

3a) Participants who receive the intervention will be more likely to perceive a need for services in the anxiety and ADHD vignettes than participants who do not receive the intervention. 3b) Participants will be more likely to perceive a need for services in the anxiety and ADHD vignettes if they or their children have had prior experience with mental illness. 3c) Participants will be more likely to perceive a need for services in the ADHD vignette if it features a boy rather than a girl. 
4) A greater proportion of participants who receive the intervention will recommend mental health services for the children featured in the anxiety and ADHD vignettes than those who do not receive the intervention. 


\section{Method}

\section{Participants}

Participants included parents living in the United States who identified as primary caregivers to children ages $3-17$. Seventeen was selected as the upper age limit for children to restrict the sample to parents who are actively involved in healthcare decisions for their children, as 18 is commonly considered the age of consent across states (Kuther, 2003). Three was selected as the lower age limit, as studies have found that problem behaviors present as early as age three are moderately stable over time (Pihlakoski et al., 2006; Sourander et al., 2006; Mesman \& Koot, 2001). Participants were recruited from preschools, public middle schools, family centers, mental health centers, an online literacy program, social networking sites, and snowball methods. Recruitment strategies included direct emails, printed flyers, and posts on social media sites containing a link to the online study. To preserve anonymity, study participants were not required to identify their recruitment source. 438 participants completed at least part of the study and were entered into a drawing for one of four \$25 Amazon gift cards. A total of 140 were excluded from final analysis. Sixty-eight of those participants were excluded because they did not meet one or more of the following eligibility criteria: 1) participant reported being under 18 years old, 2) participant did not have a child between the ages of 3 and 17, or

3) participant did not identify as a primary caregiver. Forty-eight participants were excluded based on incorrect responses to two screener questions that assessed comprehension and memory of pamphlet content to ensure that participants in the intervention condition paid sufficient attention to the pamphlet. Twenty-four 
additional participants dropped out before completing the survey (15 in the intervention group and 9 in the control group). The final sample consisted of 298 participants, $123(41.3 \%)$ in the intervention group, and $175(58.7 \%)$ in the control condition (see Figure 1). Those excluded from analysis were more likely to be unemployed, have fewer children, and have a lower household income, and they were less likely to identify as White.

\section{Measures}

Demographics. Participants were asked to report their gender, age, race, ethnicity, marital status, annual income, employment status, education level, and number of children in the home. They also reported the ages and genders of all their children between the ages of 3-17. Participants were asked whether they identify as their children's primary caregiver and what their relation is to their children (e.g., biological, adoptive, stepparent, etc.). Demographic questions can be found in Appendix A.

Vignettes. Participants were presented with three vignettes constructed by Thurston and colleagues (2015), which can be found in Appendix B. Each vignette depicted a 10-year-old child, selected due to developing importance of social awareness and academic success at this age, and parents were randomly assigned to read about a boy or a girl. One vignette featured a child exhibiting behavior consistent with a DSM-IV diagnosis of anxiety, one featured a child exhibiting behavior consistent with ADHD, and one featured a child exhibiting typical behavior with no clinical diagnoses. Anxiety and ADHD were selected to represent an internalizing disorder and an externalizing disorder, respectively, and represent two of the most 
prevalent childhood mental health conditions (Kessler et al., 2005). Inclusion of a typical behavior vignette served as a check to ensure that the intervention led to accurate problem recognition rather than overidentification of perceived problematic behavior. These vignettes were previously assessed by a panel of clinicians specializing in child and family work and were approved for authenticity of symptoms and legitimacy of diagnoses (Thurston et al., 2015).

Problem severity. Participants were asked a series of questions derived from Thurston and colleagues' (2015) study after each vignette, including, "How seriously would you rate this child's problems compared to other 10-year-olds?", "How concerned would you be about this child's problems?", "How much do you think these problems would affect this child's daily activities?", and, "How much do you think these problems would impact this child's family?" Participants ranked each question on a 5-point Likert scale from 1 (not at all) to 5 (extremely). Responses were summed to provide a continuous score for problem severity with a possible range of 4 to 20 .

Problem recognition. Parents were asked to answer yes or no to the question, "Do you think this child has a mental health problem?" This question was repeated after each vignette to provide separate reports of problem recognition for the anxiety vignette, the ADHD vignette, and the typically-developing child (TDC) vignette.

Perceived need for services. After each vignette, participants were asked to answer yes or no to the question, "If you were responsible for this child, would you seek help for him?"

Recommendations for services. Participants were asked to identify the sources of help they would recommend for each child depicted in the vignettes. 
Options included psychologist/counselor/therapist, psychiatrist/psychiatric nurse, primary care physician/other medical doctor, inpatient hospital/day program, guidance counselor/school psychologist, teacher/other school staff member, social worker/case manager, religious leader, crisis hotline, support group, family, friends, searching the Internet/reading a book, or other. Participants were allowed to select more than one response. See Appendix C for problem severity, problem recognition, perceived need for services, and service recommendation questions.

Experience with mental illness. Participants were asked dichotomously whether they had a personal history of mental health issues. They were then presented with a list of common disorders and asked to select all conditions they had experienced. Options included anxiety disorder, depressive disorder, ADHD, oppositional defiant disorder, autism spectrum disorder, substance use problems, posttraumatic stress disorder (PTSD), tic disorder, or other. Participants who endorsed a personal history of mental health issues were asked if the problem was formally diagnosed and whether they sought help. Those who endorsed help-seeking were presented with a list of commonly utilized sources of support and asked to identify which they used (e.g., mental health specialists, medical professionals, religious leaders, books/web sites, etc.).

Participants also reported whether any of their children had experienced mental health issues and selected all applicable conditions from a given list. They were asked to identify whether they sought help for their child and to select the services they utilized from a list of common sources of help for children's mental health issues. Lastly, participants were asked if they had a romantic partner with a history of mental 
health problems. Participants were coded as having experience with mental health issues if they endorsed either a personal history of mental illness, a child's history of mental illness, or a partner's history of mental illness.

For exploratory purposes, participants were presented with open-ended questions about past experiences with mental health issues. For example, if they endorsed a personal history or a child's history of mental illness, they were asked to comment on how they knew a problem was present. If they endorsed having sought help for themselves or for their child, they were asked how they knew help was needed and how they decided where to seek help. They were also asked to comment broadly on their experiences of help-seeking, as well as to identify which sources they typically use to learn about child-rearing and child development. See Appendix D for study questions pertaining to mental health experience.

\section{Pamphlet Design}

Social comparison theory posits that individuals compare themselves to others to evaluate their own standing (Festinger, 1954). In the children's mental health literature, parents tend to evaluate their children's behaviors by comparing them to siblings or same-aged peers (e.g., Marshall et al., 2016; Glascoe \& MacLean, 1990). Parents also tend to have an easier time identifying concerns when guided to reflect on specific domains of development, such as social, emotional, or behavioral (Glascoe \& Marks, 2011). Therefore, the information provided in the pamphlet followed a "developmental milestone" model that encouraged parents to anchor their child's behavior to age-normative behavior. More accurate expectations and understanding of 
normative behavior in children may empower parents to identify next steps to managing problem behavior.

Problem behaviors were referred to in the pamphlet as "on-track" or "offtrack" to help parents delineate between normative and non-normative childhood struggles. On-track problem behaviors are described as follows: "On-track problem behaviors happen sometimes. On-track problem behaviors go away after a while. Ontrack problem behaviors don't get in the way of your child's life or your life." Offtrack problem behaviors are described as follows: "Off-track problem behaviors happen a lot of the time. Off-track problem behaviors don't go away for a long time. Off-track problem behaviors get in the way of your child's life or your life."

Alongside guidelines for problem recognition, the pamphlet provided evidence-based information about children's mental healthcare utilization and outcomes with the goal of shifting parents' focus from normalizing the problem behavior to normalizing treatment. The pamphlet was designed to avoid psychological jargon to appeal to a wider audience, as the target population for this psychoeducation included parents who may have minimal experience with mental health issues. The pamphlet can be found in Appendix E.

\section{Procedure}

All data were collected with Qualtrics Survey Software (Qualtrics, 2017). Participants followed a link to an online survey, where they completed an electronic consent form and provided demographic information. Participants were randomly assigned to the intervention group or the control group. Those assigned to the intervention group viewed a one-page pamphlet providing information about 
normative child development and problem identification. Participants were asked to read the pamphlet carefully and answer a few questions, e.g., how helpful they found the information, how well they understood the information, and how relevant the information felt for their child. Two questions about the information included in the pamphlet assessed for sufficient attention to the material and were used to identify random or careless responding. Participants who did not answer these questions correctly were excluded from analyses.

All participants, regardless of experimental group, viewed each of the vignettes. The order of the vignettes was counterbalanced, and character gender in each vignette was assigned randomly. Participants were asked questions about problem recognition and perceived need for services after each vignette. They then

provided information about family experience with mental illness. Upon completion of data collection, participants were given the opportunity to submit their email address for entry into a raffle for an Amazon.com gift card.

\section{Data Analytic Plan}

All statistical analyses were conducted using IBM SPSS Statistics version 24 (IBM Corp., 2016). A series of independent samples $t$-tests and chi-square tests of independence were conducted on all demographic variables to test for unintended differences between randomly assigned experimental groups and associations with primary outcome variables, including problem recognition, problem severity, and perceived need for services. Analyses pertaining to specific hypotheses will be discussed in the corresponding results section. 
Missing Data. SPSS Missing Values Analysis explored patterns of missing data among demographic variables. Just over $1 \%$ of participants did not report on their ethnicity. To examine whether these data were missing at random, independentsamples t-tests and chi-squared analyses were conducted to compare observed and missing data across primary study variables. No significant relationship was found between these missing data and problem recognition, $\chi^{2}(1, N=298)=.009-1.28, p=.26-$ .92 , problem severity, $t(296)=-1.33--1.14, p=.18-.42$, perceived need for services, $\chi^{2}(1$, $N=298)=.17-.59, p=.45-.68$, mental health experience, $\chi^{2}(1, N=298)=1.47, p=.22$, or mental health services recommendation, $\chi^{2}(1, N=298)=.58-1.77, p=.18-.45$. Therefore, missing data appear to be convincingly missing at random and are not expected to bias the results.

Pairwise deletion was used to manage missing data. Although this method has raised some concern in the literature given possible distortions in parameter estimates (Little, 1992; Baraldi \& Enders, 2010), pairwise deletion preserves statistical power and has been deemed appropriate when missing data are random and correlations are low to moderate (Pigott, 2001; Higgins \& Green, 2011). In this study, ethnicity, the variable with the highest rate of missing data, was most strongly correlated with problem severity in the TDC vignette, $r(296)=-.18, p=.003$. According to Cohen's (1988) guidelines, this correlation demonstrated a small to moderate effect size, thus upholding recommendations for pairwise deletion. Additionally, our sample evidenced very low rates of missing data; therefore, the selected method of handling missing data is unlikely to have significant effects on results. 
Data assumptions. Tests of group differences assume that continuous data are linear, normal, and homoscedastic. Preliminary analyses of means, standard deviations, skewness, and kurtosis suggest that problem severity ratings across vignettes are normally distributed (see Table 1). 


\section{Results}

\section{Power Analyses}

An a priori power analysis using $\mathrm{G}^{*}$ Power 3.1 (Faul et al., 2007) was conducted for the planned logistic regression analyses that identified predictors of problem recognition and perceived need for services. The power analysis was designed to assume two-tailed $p$ values, a small effect size with odds ratio $=1.6$ based on averages across relevant literature, and power $=.80$. This analysis revealed that at least 143 total participants were required in order to detect medium effect sizes.

A second a priori power analysis was conducted for the planned ANCOVA analyses that looked at differences in problem severity across predictor variables. Assuming two-tailed $p$ values, six groups (two per main binary predictor), a medium effect size based on the literature reviewed above, and power $=.80,158$ participants were required to yield sufficient power.

These findings fall in line with recommendations from Harlow (2014) that predict a sample size of 160 would yield sufficient power to detect significant group differences given these planned analyses.

\section{Descriptive Statistics}

Demographic variables. Of the 298 participants included in analyses, 267 $(89.6 \%)$ were female and $31(10.4 \%)$ were male. Participants ranged in age from 24 to $58(M=40.8, S D=6.98)$. Thirty-eight $(12.8 \%)$ identified as Hispanic/Latino, 255 identified as non-Hispanic/Latino, and the remaining 5 participants $(1.7 \%)$ did not report ethnicity. The racial breakdown of the sample included $268(89.9 \%)$ White/Caucasian, seven (2.3\%) Asian, five (1.7\%) Black/African American, and four 
(1.3\%) Native American/Alaska Native participants. Fifteen participants (5\%) identified their race as "Other."

Participants were predominantly married or in a domestic partnership ( $N=261$, $87.6 \%)$, and had earned a graduate or professional degree $(N=138,46.3 \%)$ or a bachelor's degree $(N=95,31.9 \%)$. Thirty-four participants $(11.4 \%)$ were students at the time of data collection. While most worked full-time $(N=175,58.7 \%)$, a substantial minority worked part-time $(N=57,19.1 \%)$ or were not seeking employment $(N=50$, $16.8 \%)$. A majority had a spouse or romantic partner who worked full-time $(N=225$, $75.5 \%$ ) and reported an annual household income of $\$ 100,000$ or more per year $(N=190,63.7 \%)$

Participants had between one and six children $(M=2.28, S D=0.95)$, with anywhere from zero to six living in the home $(M=2.09, S D=0.88)$. Participants generally reported equal numbers of male $(M=1.51, S D=0.77)$ and female $(M=1.44$, $S D=0.74$ ) children. While the vast majority reported that they were a biological parent to at least one of their children, $(N=286,96 \%), 13$ identified as an adoptive parent $(4.4 \%), 12$ as a stepparent (4\%), four as a foster parent $(1.3 \%)$, and one as a grandparent $(0.3 \%)$. An additional six participants $(2 \%)$ reported other relationships to the child or other parenting circumstances, such as using a donor egg.

Independent-samples t-tests and chi-square tests of independence were performed to compare demographic variables in the control and intervention conditions (see Table 2). The only demographic variable that evidenced a significant difference between the control group and the intervention group was the number of female children. Participants in the intervention condition had more female children 
$(M=1.59, S D=0.83)$ than did participants in the control group $(M=1.34, S D=0.66)$, $t(155.57)=-2.45, p=0.16$. However, number of female children was not significantly correlated with any major study variables, including problem recognition (Anxiety: $r(223)=.014, p=.83$; ADHD: $r(223)=.089, p=.19$; TDC: $r(223)=.13, p=.054)$, problem severity (Anxiety: $r(223)=-.12, p=.081$; ADHD: $r(223)=-.13, p=.06$; TDC: $r(223)=.020, p=.77$ ), perceived need for services (Anxiety: $r(223)=-.030, p=.65$; ADHD: $r(223)=-.013, p=.85$; TDC: $r(223)=.061, p=.36)$, gender of child in each vignette (Anxiety: $r(223)=.044, p=.51$; ADHD: $r(223)=-.001, p=.99$; TDC: $r(223)=$ $-.031, p=.55)$, or mental health experience $(r(223)=.004, p=.96)$. Therefore, this variable was not covaried in further analyses.

One hundred and fifty-eight participants (53\%) had some experience with mental health issues, meaning that either they, one of their children, or a spouse or partner had suffered from a mental health condition in the past or present. Eightyseven participants (29\%) endorsed a personal history of mental health issues, with 60 $(20.1 \%)$ reporting a history of anxiety and $14(4.7 \%)$ reporting a history of ADHD. Significantly more participants endorsed a personal history of anxiety compared to ADHD, $Z=5.72, p<.001$, and females exhibited a higher prevalence of both conditions than males. Fifty-eight female participants (27.8\%) endorsed a history of anxiety compared to only two male participants $(6.5 \%)$, and 14 females $(4.7 \%)$ endorsed a history of ADHD compared to 0 males.

Furthermore, 86 participants (29\%) reported that their children had a history of mental health issues; 53 participants $(17.8 \%)$ had at least one child with anxiety and 38 participants (12.8\%) had at least one child with ADHD. There was a trend towards 
higher rates of anxiety than ADHD in participants' children, $Z=1.71, p=.087$.

Additionally, 22\% $(N=66)$ reported having a spouse or romantic partner with a history of mental illness.

Participant response to pamphlet. Participants who read the pamphlet reported that the information was very easy to understand $(M=4.09, S D=.90$, possible range 1-5). Reports were mixed regarding how helpful they found the information ( $M=2.85, S D=.89)$ or how relevant it was to their child $(M=2.54, S D=.99)$, with average reports falling between a little and somewhat.

\section{Hypothesis One: Problem Recognition}

Overview of Findings. Multivariate logistic regressions were employed to assess whether experimental condition, mental health experience, and/or assigned gender of the character in the vignette predicted which participants correctly identified a problem and which did not. Tables 3-5 show percentages of participants who recognized a problem based on these variables across vignettes. Bivariate correlations were used to identify demographic variables that were significantly associated with problem recognition, and any such variables were included in the multivariate analysis. Tables 6-8 show the logistic regression coefficient, Wald test, and odds ratio with $95 \%$ confidence interval for all predictors in each model. Odds ratios were used to approximate effect size, as reliance on pseudo $r^{2}$ s has been met with criticism due to variability across measures (Hoetker, 2007). Chen and colleagues (2010) recommend using an odds ratio of 1.68 to correspond to Cohen's $d=.2$ (a small effect size), odds ratio of 3.47 to correspond to Cohen's $d=.5$ (a medium effect size), and odds ratio of 
6.71 to correspond to Cohen's $d=.8$ (a large effect size). This model was used in the current study to interpret effect sizes.

Overall, a majority of participants identified problematic behavior in the anxiety vignette (62.1\%). A smaller majority recognized problematic behavior in the ADHD vignette (55\%). The difference in these proportions is marginally significant, $Z=1.75, p=.08$. This finding contrasts the results presented by Thurston and colleagues (2015), who found that caregivers more often recognized a problem in the ADHD vignette $(61 \%)$ compared to the anxiety vignette (52\%). Only 5\% of participants identified a significant problem in the typically developing child (TDC) vignette. This vignette was specifically written to highlight typical areas of difficulty for most children without connoting clinical significance, therefore it was expected that very few participants would report a problem in this condition.

In the anxiety vignette, several demographic variables were significantly associated with problem recognition and thus included in the multivariate logistic regression model. Identifying as White, $\chi^{2}(1, N=298)=6.91, p=.009$, and/or a woman, $\chi^{2}(1, N=298)=8.03, p=.005$, was associated with higher rates of problem recognition, while identifying as Hispanic, $\chi^{2}(1, N=293)=4.035, p=.045$, and/or Asian, $\chi^{2}(1$, $N=298)=6.96, p=.008$, was associated with lower rates of problem recognition. The following binary demographic variables were therefore included in the model: Ethnicity (Non-Hispanic/Latino vs. Hispanic/Latino), Gender (Male vs. Female), White/Caucasian (No vs. Yes), and Asian (No vs. Yes). A test of the full model versus a model with only the intercept was statistically significant, $\chi^{2}(7, N=293)=42.34$, 
$p<.001$. The model was able to correctly classify $90 \%$ of those who identified a problem and $24 \%$ of those who did not, for an overall success rate of $65 \%$.

No demographic variables exhibited a significant bivariate correlation with problem recognition in the ADHD vignette; therefore, the model solely consisted of the main predictors (experimental condition, mental health experience, and character gender). The omnibus effect of the model was again significant, signifying that the model has greater predictive power than the intercept alone, $\chi^{2}(3, N=298)=16.35, p=$ .001 . Specifically, the model correctly identified $74 \%$ of participants who identified a problem and $52 \%$ of those who did not, with an overall success rate of $64 \%$.

In the TDC vignette, identifying as a stepparent was associated with greater rates of problem recognition, $\chi^{2}(1, \mathrm{~N}=298)=10.38, p=.001$; therefore, this variable was included as a predictor in the full model. Considering experimental condition, mental health experience, character gender, and identifying as a stepparent, the omnibus effect of the model fell short of significance, $\chi^{2}(4, N=297)=8.77, p=.067$.

Hypothesis 1a: Intervention. It was predicted that those receiving the intervention would be more likely to recognize problem behaviors in the anxiety and ADHD vignettes than those who did not. Contrary to our hypothesis, receiving the intervention did not improve participants' problem recognition skills in either the anxiety or ADHD vignettes ( $p=.35-88)$. Similarly, receiving the intervention did not influence problem recognition skills in the TDC vignette $(p=.51)$.

Hypothesis 1b: Mental Health Experience. We predicted that participants who had a personal or familial history of mental health issues would exhibit higher rates of problem recognition in the anxiety and ADHD vignettes. This hypothesis was 
fully supported. In the anxiety vignette, when holding all other variables in the model constant, those with mental health experience were 3.16 times more likely to accurately recognize a problem than those without such experience. According to Chen and colleagues (2010), this odds ratio approaches a medium effect size. Univariate analyses revealed that $75 \%$ of those with a personal or familial history of mental health issues recognized a problem, compared to $48 \%$ of those without such experience, $\chi^{2}(1, N=298)=22.69, p<.001$.

In the ADHD vignette, those with personal or familial histories of mental health issues were 2.43 times more likely than those without to accurately recognize problem behavior in this vignette, suggesting a small to medium effect of mental health experience. Univariate analyses revealed that $65 \%$ of participants with mental health experience identified problematic behavior, compared to only $44 \%$ of those without mental health experience, $\chi^{2}(1, N=298)=14.02, p<.001$.

The influence of mental health experience on problem recognition was also assessed for the TDC vignette. Univariate analyses found that those with mental health experience trended towards higher problem recognition rates $(7 \%)$ compared to those without ( $3 \%$ ), but this finding fell short of significance at the $\alpha=.05$ level, $\chi^{2}(1$, $N=297)=2.66, p=.10$.

Hypothesis 1c: Character Gender. It was predicted that participants would be more likely to recognize problem behaviors in the ADHD vignette if the vignette featured a male character than if it featured a female character. A greater proportion of participants identified a problem in this vignette when assigned a male character $(58.7 \%)$ versus a female character $(51.4 \%)$, but this difference did not achieve 
significance $(p=.20)$. Therefore, our hypothesis was not supported. Character gender also did not predict problem recognition in the anxiety or TDC vignettes.

Additional Findings. In the anxiety vignette, participant gender emerged as a significant predictor of problem recognition, as women were 3.36 times more likely to correctly identify a problem than men. This odds ratio nears a medium effect size. Univariate analyses show that $65 \%$ of women recognized a problem in this vignette, compared to only $39 \%$ of men, $\chi^{2}(1, N=298)=8.03, p=.005$.

In the TDC vignette, those who identified as stepparents exhibited higher rates of problem recognition $(25 \%)$ than those who did not $(4 \%), \chi^{2}(1, N=297)=10.38$, $p=.001$. Though the effect size of stepparent identification falls into the large range, the small number of stepparents in our study $(N=12)$ and the notably wide confidence interval of the odds ratio (1.47 to 27.69) suggest that this finding should be interpreted with caution.

\section{Hypothesis 2: Problem Severity}

Overview of Findings. Independent t-tests assessed group differences in reported problem severity. Separate tests were run to analyze the effects of experimental condition, past mental health experience, and character gender on problem severity in the anxiety vignette. Variables that emerged as significant were included in a factorial analysis of co-variance (ANCOVA) that controlled for demographic variables associated with problem severity in each vignette. The following rule of thumb was used to interpret effect sizes: $\eta_{\mathrm{p}}{ }^{2}=.01$ (small), $\eta_{\mathrm{p}}{ }^{2}=.06$

(medium), $\eta_{\mathrm{p}}{ }^{2}=.14$ (large; Cohen, 1988). Problem severity evidenced normal distribution across each predictor. Homogeneity of variance was upheld across 
analyses with the exception of mental health experience in the ADHD vignette. To compensate for the violation of this assumption, degrees of freedom were adjusted.

Overall, participants rated problem severity higher in the anxiety $(M=14.84$, $S D=2.31)$ and $\operatorname{ADHD}(M=14.70, S D=2.54)$ vignettes compared to the TDC vignette $(M=7.6, S D=2.81)$. There was no meaningful difference in the sample-wide problem severity ratings for the anxiety vignette compared to the ADHD vignette, $t(297)=.90$, $p=.37$. Participants with more children demonstrated decreasing rates of problem severity in the anxiety and ADHD vignettes, (anxiety: $r(296)=-.13, p=.023$; ADHD: $r(296)=-.13, p=.026)$. More specifically, number of male children was negatively associated with problem severity in the anxiety vignette, $r(234)=-.16, p=.017$, and number of children living with the participant was negatively associated with problem severity in the ADHD vignette, $r(296)=-.13, p=.026$. Identifying as a student also led to lower ratings of problem severity, but only in the ADHD vignette, $r(296)=-.15$, $p=.011$. In the TDC vignette, identification as Hispanic/Latino was positively associated with problem severity, $r(291)=.18, p=.002$.

Hypothesis 2a: Intervention. It was predicted that those receiving the intervention would rate problem severity higher in the anxiety and ADHD vignettes than participants assigned to the control group. Contrary to our hypothesis, the intervention did not effect significant change in problem severity in either of these vignettes. However, the intervention did have an effect on problem severity in the TDC vignette, $\mathrm{t}(296)=2.16, p=.031$. Specifically, those receiving the intervention $(M=7.19, S D=2.51)$ reported lower problem severity than those assigned to the control group $(M=7.90, S D=2.97)$. However, when controlling for ethnicity, assignment to the 
intervention condition was no longer a significant predictor at the $\alpha=.05$ level, $F(1$, $290)=3.52, p=.062, \eta_{\mathrm{p}}{ }^{2}=.012$. Findings show a trend, however, which suggests that viewing the pamphlet may have had some impact on participants' recognition that the problem behaviors described in the TDC vignette were not "off-track."

Hypothesis 2b: Mental Health Experience. Past experience with mental health issues was expected to lead to increased ratings of problem severity in the anxiety and ADHD vignettes. We were correct in our prediction that those with mental health experience $(M=15.02, S D=2.36)$ reported higher problem severity than those without such experience $(M=14.34, S D=2.70)$ in the ADHD vignette, $\mathrm{t}(277.82)=-2.31$, $p=.021$ (note: degrees of freedom were adjusted from 296 to 277.82 as Levene's test indicated unequal variances, $F=6.71, p=.01)$. However, mental health experience did not influence problem severity ratings in the anxiety vignette, nor the TDC vignette. Thus, this hypothesis was only partially supported.

Hypothesis 2c: Character Gender. It was predicted that participants assigned to a male character in the ADHD vignette would report higher problem severity than those assigned a female character. This hypothesis was fully supported: those assigned a male character $(M=15.07, S D=2.57)$ in the ADHD vignette reported higher problem severity in than those assigned a female character $(M=14.32, S D=2.47), \mathrm{t}(296)=2.54$, $p=.011$. Character gender did not influence problem severity in the anxiety or TDC vignettes.

Additional Findings. As no main predictors emerged as significant predictors of problem severity in the anxiety vignette, a factorial ANCOVA was not run. However, ordinary least squares (OLS) regression analyses explored the effect of 
demographic variables on problem severity. Number of children approached but did not achieve significance, $F(2,233)=2.90, p=.057$, but having more male children did significantly predict lower reports of problem severity in the anxiety vignette, $F(1$, $234)=5.77, p=.017$. No such association emerged for number of female children.

In the ADHD vignette, between-subjects factors mental health experience (no, yes) and character gender (male, female) were imputed into a 2x2 ANCOVA that controlled for demographic variables. Homogeneity of variances was upheld in the full model, and small to medium main effects remained for both variables (mental health experience: $\mathrm{F}(1,291)=6.14, p=.014, \eta_{\mathrm{p}}{ }^{2}=.021$; character gender, $\mathrm{F}(1,291)=5.12$, $\left.p=.024, \eta_{\mathrm{p}}{ }^{2}=.017\right)$. No interaction emerged between these variables, $\mathrm{F}(2,291)=.591$, $p=.44, \eta_{\mathrm{p}}{ }^{2}=.002$ (see Figure 2). Current status as a student remained a significant predictor of decreased problem severity ratings in the ADHD vignette, $F(1,291)=4.35$, $p=.038, \eta_{\mathrm{p}}{ }^{2}=.015$, but total number of children $(p=.43)$ and number of children living with the participant $(p=.46)$ were no longer significant when considering the other variables in the model.

In the TDC vignette, an ANCOVA was run with between-subjects factor condition (control, intervention) and covariate ethnicity (Hispanic/Latino, nonHispanic Latino). Homogeneity of variances was upheld. As mentioned, the effect of the intervention was no longer significant when controlling for ethnicity, but ethnicity remained significant with a small to medium effect size, $F(1,290)=8.46, p=.004$, $\eta_{\mathrm{p}}{ }^{2}=.028$. Those who identified as Hispanic/Latino reported higher problem severity $(M=8.87, S D=3.11)$ than those who identified as non-Hispanic/Latino $(M=7.40$, $S D=2.73$ ). See Figure 3 for visual representation of these findings. 


\section{Hypothesis 3: Perceived Need for Services}

Overview of Findings. Multivariate logistic regressions were used to analyze whether experimental group, mental health experience, and character gender predicted perceived need for services across vignettes. See Tables 9-11 for percentages of participants who recognized a need for services based on these variables.

Demographic variables that emerged as significantly associated with perceived service need were included in each model. See Tables 12-14 for more information about these models.

Overall, $89.9 \%$ of participants endorsed that the child in the anxiety vignette was in need of services, as did $89.6 \%$ of participants in the ADHD vignette. It is notable that the rate of endorsing service need far exceeded the rate of problem recognition in both vignettes (anxiety: $\chi^{2}(1, N=298)=54.61, p<.001$; ADHD: $\chi^{2}(1$, $N=298)=42.35, p<.001$ ). Among those who denied that the child in the anxiety vignette had a mental health problem, $73.5 \%(N=83)$ reported that the child would still benefit from services. Similarly, $77 \%(N=103)$ of those who denied a problem in the ADHD vignette still endorsed a need for services. $13.8 \%$ reported a perceived need for services in the typically developing child vignette, which similarly represents an increase from the percentage who recognized a problem in this vignette $(5 \%)$.

In the anxiety vignette, participants who identified as female more often indicated that the child needed services, $\chi^{2}(1, N=298)=13.75, p<.001$; thus, participant gender was included in the logistic regression. The omnibus effect of the model was significant, $\chi^{2}(4, N=298)=16.03, p=.003$; however, the addition of these predictors did not improve accuracy of classification (overall success rate remained 89.9\%). This 
stagnancy is likely explained by the extremely high base rate of perceived need for services in this vignette.

Participant age emerged as significantly correlated to perceived need for services in the ADHD condition, $r(295)=.12, p=.041$, and was thus entered into the logistic regression model. The omnibus effect of the model was significant, $\chi^{2}(4$, $N=297)=18.80, p=.001$, but again, the full model did not improve upon accuracy of classification.

Several racial/ethnic variables emerged as significantly related to perceived need for services in the TDC vignette. Those who identified as Hispanic were more likely to identify a need for services, $\chi^{2}(1, N=293)=8.67, p=.003$, and those who identified as White were less likely to identify a need for services, $\chi^{2}(1, N=298)=7.42$, $p=.006$. Additionally, those who identified as a race other than those listed (i.e., White/Caucasian, Black/African American, Asian, Native Hawaiian/Pacific Islander, or Native American/Alaska Native) were more likely to identify service need, $\chi^{2}(1$, $N=298)=5.101, p=.024$. As such, these demographic variables were included in the logistic regression model. However, the omnibus effect fell short of significance at the $\alpha=.05$ level, $\chi^{2}(6, N=293)=10.95, p=.09$.

Hypothesis 3a: Intervention. It was predicted that assignment to the intervention condition would predict higher perceived need for services in the anxiety and ADHD vignettes. This hypothesis was not supported, as the intervention had no effect on perceived need for services in either vignette ( $p=.35-.48)$. Similarly, assignment to the intervention condition did not affect reports of service need in the TDC vignette $(p=.60)$. 
Hypothesis 3b: Mental Health Experience. It was expected that participants with mental health experience would be more likely to identify a need for services in the anxiety and ADHD vignettes. This hypothesis was fully supported. Those with mental health experience were 2.34 times more likely to identify a need for services in the anxiety vignette (small to medium effect), as $94 \%$ of those with mental health experience perceived a need for services compared to $86 \%$ of those without, $\chi^{2}(1$, $N=298)=5.19, p=.023$. Participants with mental health experience were even more likely to identify a need for services in the ADHD vignette (odds ratio $=4.98$, small to medium effect size). $95.6 \%$ endorsed service need compared to only $82.9 \%$ of participants with no such experience, $\chi^{2}(1, N=298)=12.87, p<.001$. Mental health experience did not predict perceived need for services in the TDC vignette.

Hypothesis 3c: Character Gender. It was predicted that participants would perceive a need for services at higher rates in the ADHD vignette if assigned a male character. Contrary to this hypothesis, character gender did not emerge as a significant predictor of service need in any of the vignettes $(p=.40-.90)$.

Additional Findings. Consistent with the results for problem recognition, participant gender significantly predicted perceived need for services in the anxiety vignette when holding all other variables constant. Female participants were 4.98 times more likely than male participants to endorse service need. All together, $92 \%$ of female participants perceived a need for services, compared to $71 \%$ of men, $\chi^{2}(1$, $N=298)=13.75, p<.001$.

Identifying as Hispanic/Latino was a significant predictor in the TDC vignette, as $28.9 \%$ of this subgroup endorsed need for services, compared to $11.4 \%$ of other 
participants, $\chi^{2}(1, N=298)=8.67, p=.003$. This finding is consistent with the aforementioned increase in problem severity ratings by Hispanic/Latino participants in this vignette.

\section{Hypothesis 4: Service Recommendations}

Overview of Findings. Mental health recommendation was defined as recommending one or more of the following services: psychologist, psychiatrist, inpatient unit, crisis hotline, or support group. Overall, $74.2 \%$ of participants recommended a mental health service for the child described in the anxiety vignette, but only $63.8 \%$ in the ADHD vignette. Participants were thus more likely to recommend mental health services for behaviors consistent with anxiety compared to behaviors consistent with ADHD, $Z=2.7, p=.006$. Only $9.4 \%$ of participants recommended a mental health service for the child in the TDC vignette.

Intervention. Chi-square tests of independence assessed whether experimental group assignment influenced service recommendations. Participants receiving the intervention were expected to recommend mental health services for the children in the anxiety and ADHD vignettes more often than participants in the control group. However, this hypothesis was not supported, as there were only marginal differences in service recommendations between those in the intervention group (anxiety: 72.4\%; ADHD: $65.9 \%$ ) and those in the control (anxiety: 75.4\%, ADHD: 62.3\%). Similarly, the intervention evidenced no effect on overall mental health service recommendation in the TDC vignette.

However, the intervention did influence recommendation of pursuing social work services. In the anxiety vignette, approximately twice as many participants in the 
intervention group (15.4\%) recommended visiting a social worker compared to participants in the control group $(7.4 \%), \chi^{2}(1, N=298)=4.85, p=.028$. In the ADHD vignette, nearly three times as many participants recommended a social worker from the intervention group (17.9\%) versus the control group $(6.9 \%), \chi^{2}(1, N=298)=8.69$, $p=.003$. Of note, the only language used to describe service providers in the intervention was "child mental health professional."

Additional Findings. Exploratory analyses further examined service recommendation patterns. Across all vignettes, participants more often recommended pursuing a mental health service than they acknowledged a mental health problem (anxiety: $Z=3.16, p=.0016$; ADHD: $Z=2.17, p=.03$; TDC: $Z=2.17, p=.03$ ). Further, the rate at which they recommended a psychologist, specifically, marginally exceeded the rate of problem recognition (anxiety: $Z=2.80, p=.0051$; ADHD: $Z=1.66, p=.097$; TDC: $Z=1.92, p=.055)$.

Consistent with prior findings, those with mental health experience were more likely to recommend mental health services than those without in the two clinical vignettes (anxiety: $80 \%$ vs. $67 \%, \chi^{2}(1, N=298)=6.79, p=.009$; ADHD: $73 \%$ vs. $54 \%$, $\left.\chi^{2}(1, N=298)=11.86, p=.001\right)$. In the anxiety vignette, participant gender also played a role, as female participants $(76 \%)$ were more likely to recommend mental health services than male participants $(58 \%), \chi^{2}(1, N=298)=4.68, p=.031$.

Psychologists were consistently the most popular service recommendation across all vignettes (anxiety: 73\%, ADHD: 62\%, TDC: 9\%). Primary care providers were recommended more than half the time for both of the clinical vignettes, and 
guidance counselors ranked in the top three most recommended services for all three vignettes. See Table 15 for the full breakdown of service recommendations.

\section{Stages of Service Acquisition}

Additional analyses were run to check study findings against the proposed model of service acquisition described in the introduction, namely that problem recognition precedes decision to seek services, which precedes ultimate service use (Goldsmith et al., 1988).

In the current study, perceived need for services notably exceeded problem recognition in both the anxiety and ADHD vignettes. Of all the participants that perceived a need for services in the anxiety vignette, only $69 \%$ also recognized a mental health problem. However, when looking at those who recognized a problem, $100 \%$ also endorsed a need for services. Similar findings emerged in the ADHD condition. Only $61 \%$ of participants who perceived a need for services also recognized a problem, whereas $100 \%$ of those who recognized a problem also supported service use. See Tables 16 and 17 for cross-tabulations. These findings indicate that problem recognition may not necessarily precede the decision to seek services, as has been suggested in other studies (e.g., Brown et al., 2014; Godoy et al., 2014; Girio-Herrera et al., 2013).

\section{Trusted Information Sources}

Participants were asked to identify the sources they typically use to learn about child rearing and child development (See Table 18). Participants overwhelmingly reported learning this information from their pediatrician or primary care physician $(73.5 \%, N=219)$. Informal information sources were also popular, including talking to 
family members $(67.8 \%, N=202)$ or friends $(65.1 \%, N=194)$, reading books $(66.1 \%$ $N=197)$, or searching the Internet $(62.4 \%, N=186)$. Just over one third $(N=106)$ identified their child's teachers as valuable information sources, with other school staff members trailing behind $(7.4 \%, N=22)$. Approximately one quarter $(N=74)$ named a psychologist or therapist as a trusted resource. 


\section{Discussion}

Overall, our study population exhibited relatively high rates of problem recognition. More than half of parents correctly identified a mental health problem in both a vignette featuring significant symptoms of childhood anxiety and a vignette featuring significant symptoms of ADHD. These findings contrast with the literature, which has consistently demonstrated that less than half of parents recognize children's mental health problems, both in their own children and in other children depicted in fictional vignettes (Oh et al., 2015; Zwaanswijk et al., 2006; Girio-Herrera et al., 2013; Teagle, 2002; Zahner, 1992; Verhulst \& Van der Ende, 1997). Of note, the vast majority of our population also correctly ruled out mental health problems in a vignette featuring a typically developing child. Therefore, these findings are unlikely to be explained by hypersensitivity to distress. Rather, our population appears to have genuinely outperformed parents in previous studies with regard to accuracy of problem recognition.

This unusually high accuracy rate of problem recognition may be explained, in part, by the demographic make-up of the study population. Compared to the U.S. population, our participants had a particularly high level of education. Whereas only $30 \%$ of people in the nation have a bachelor's degree or higher, nearly $80 \%$ of our sample had at least a college-level education (U.S. Census Bureau, 2010). Level of education has been widely associated with mental health literacy (Furnmah et al., 2016; Steele et al., 2007; Yen et al., 2005). In fact, the lowest levels of mental health literacy have been found among males with low education levels, and males were also underrepresented in our sample (10\% compared to 49\% nationwide; Khlat et al., 2014; 
U.S. Census Bureau, 2010). These variables suggest that our population may have possessed higher-than-normal rates of mental health literacy.

Despite relatively high rates of problem recognition, parents identified mental health problems notably less frequently than they endorsed a need for services. This finding directly contradicts the service utilization model that theorizes that problem recognition, by default, precedes the decision to seek help (Goldsmith et al., 1988). In our study, $28 \%$ of participants in the anxiety vignette and $35 \%$ of parents in the ADHD vignette expressed openness to help-seeking without identifying a mental health problem. In contrast, no parents identified a mental health problem in either vignette without also endorsing a need for services. These findings indicate that conscious endorsement of a mental health problem is not a prerequisite for helpseeking.

It is possible that problem recognition was lower than perceived need for services due to the language used in the problem recognition question. The question specifically used the label mental health problem, which may have caused discomfort for some participants (see Kaushik et al., 2016). Simple shifts in language, such as describing a person with a mental illness instead of a mentally ill person, can have significant effects on bias (Granello \& Gibbs, 2016; Byrne, 2000). The term mental health may have elicited such a stigmatized response that it was less threatening for parents to consider help-seeking than to assert that a child has a mental health problem.

Additionally, parents may have felt uncomfortable in the role of “diagnostician", as the problem recognition question required a Yes/No response to 
the question, "Do you think (insert child name) has a mental health problem?” In reality, symptoms of anxiety and ADHD are dimensional, and parents may not have felt comfortable determining whether symptoms meet criteria for a diagnosis. Parents who felt conflicted, either about the terminology or their own problem recognition skills, may have opted for the null response to ease their cognitive dissonance.

It is also possible that parents do not categorize these difficulties as "mental health" problems. Particularly with ADHD, parents may more readily identify symptoms as signifying a behavioral or learning problem (Sayal et al., 2006). That said, rates of recommending mental health services, including a psychologist, psychiatrist, inpatient unit, crisis hotline, or support group, were notably high. In fact, across all three vignettes, significantly more parents specifically recommended pursuing a mental health service than acknowledged that the child had a mental health problem. Specifically, parents tended to recommend that the children in the vignettes see a psychologist, which is arguably the prototypical mental health professional. Parents' almost unanimous help-seeking recommendations in the anxiety and ADHD vignettes, coupled with the high rate of recommending a psychologist, specifically, suggests that assessing for problem recognition alone underestimates parents' awareness of children's mental health problems and need for intervention.

\section{Effectiveness of the Intervention}

Results suggest that viewing the pamphlet did not increase parents' problem recognition skills. Participants assigned to the intervention group did not outperform participants assigned to the control group in accurate problem identification in any of the three vignettes. Similarly, parents receiving the intervention exhibited no 
difference in perceived need for services across vignettes. The only group difference attributable to the intervention was a marginal shift in perceptions of problem severity for the non-clinical vignette. Those receiving the intervention reported lower levels of problem severity for the typically developing child than those in the control group. Though this finding no longer achieved significance when controlling for ethnicity, a trend remained.

The goal of the intervention was to help parents overcome the welldocumented tendency to normalize problem behaviors that are consistent with children's mental health problems. Yet, the only notable effect of the intervention appears to be increased normalization of problems in a typically developing child. It is possible that presentation of material about mental illness, a highly stigmatized subject, triggered defensiveness in parents. The information in the pamphlet divides problem behaviors into "on-track" and "off-track" to help parents distinguish between the transient struggles of childhood and those possibly representing a need for intervention. However, to resolve distress associated with reflecting on children's mental health issues, parents may have over-attended to the information promoting detection of "on-track" problem behaviors, similar to those represented in the TDC vignette. While it is impossible to assess the cognitive processes of parents completing this study, such a pattern of shifting perceptions of problem severity to resolve cognitive dissonance has been echoed in other studies of child and adolescent problem behaviors (e.g., Glatz et al., 2012; Thomson et al., 2014; Lindsey et al., 2013). As in previous studies, parents may have over-normalized the problems presented in the vignettes to the point of limiting increased problem recognition when indicated. 
Several other explanatory factors are worth consideration. It is possible that high rates of mental health literacy in our sample limited the effectiveness of a brief intervention, as the information presented in the pamphlet may have been redundant for many participants. Despite finding the information easy to understand, many found it to be only marginally helpful. The intervention may have been more impactful with an audience that was less familiar with mental health issues.

Another consideration is the broad scope of the intervention. The pamphlet was designed to increase awareness of children's mental health issues in general, rather than to focus on a specific disorder or problem type. Rather than inform the reader about specific symptoms or red flags, the pamphlet provided a framework for problem identification that parents could apply across the behavioral and emotional spectrum. However, it may have been difficult for parents to apply this broad framework to specific mental health conditions, especially considering the brevity of exposure to the pamphlet content.

Additionally, the decision to format this information as a one-page pamphlet rather than a longer or more involved intervention may have limited its impact. The pamphlet was intentionally designed to be brief. Minimizing length was expected to encourage wider readership, as parents who are not actively concerned about mental health issues may be unlikely to invest time and energy into increasing their mental health literacy, as well as to reduce costs of dissemination. However, in reviewing the literature, interventions to increase mental health literacy tended to be more effective as the level of engagement increased. Studies using support groups, workshops, and online courses to increase mental health literacy have been largely successful (e.g., 
Umpierre et al., 2015; Harrison et al., 2016; Sebbens et al., 2016; and Taylor-Rodgers \& Batterham, 2014), but studies depending on brief, written materials have found less support for efficacy (e.g., Dueweke \& Bridges, 2017; Hay et al., 2007). The pamphlet used in the current study may have been too brief to be effective, suggesting that it provided a "sub-therapeutic dose" of information about problem detection.

\section{Mental Health Experience}

As we predicted, a personal or familial history of mental health issues consistently predicted problem recognition, perceived need for services, and recommendation to see a mental health professional in both the anxiety and ADHD vignettes. Participants who did not have mental health experience exhibited problem recognition rates that more closely approximated what have been reported in previous studies (e.g., Oh et al., 2015; Teagle, 2002; Girio-Herrera et al., 2013). In contrast, problem recognition among those with past or current exposure to mental illness was about 50\% higher in both clinical vignettes. Additionally, those with mental health experience rated problem severity higher in the ADHD vignette than those without. These findings lend credence to the theory that the personal experience of identifying problem behaviors, seeking services, and navigating the treatment process increases mental health literacy (Mendenhall \& Frauenholtz, 2015; Schofield et al., 2016; Thurston et al., 2015).

Notably, rates of mental health experience in our population slightly exceed the national average ( $29 \%$ of both participants and their children compared to $20 \%$ of adults and children nationwide; NIMH, 2015a; NIMH, 2015b), which may contribute 
to relatively strong awareness of signs and symptoms of mental health issues observed across our sample.

\section{Gender}

Notable gender patterns emerged across findings. In the anxiety vignette, female participants were more likely to recognize a problem, perceive a need for services, and recommend seeing a mental health professional than male participants. However, there were no gender differences in ratings of problem severity. These findings suggest that women in our study had a better understanding than men that the symptoms described in the vignette signaled the presence of a mental health disorder, rather than that women were more sensitive or attuned to the symptoms themselves. There is strong evidence in the literature that women tend to exhibit stronger mental health literacy than men (e.g., Georgakakou-Koutsonikou \& Williams, 2017; Mendenhall \& Frauenholtz, 2015; Picco et al., 2016). Even among middle-schoolers, girls tend to show higher mental health literacy and openness to help-seeking compared to boys (Olsson \& Kennedy, 2010).

Of note, this finding was specific to the anxiety vignette and was not replicated in the ADHD vignette. Internalizing disorders are more prevalent among women than men, particularly in adolescence and adulthood (see Zwaanswijk et al., 2003; Kessler

et al., 2005). In our study, more than one out of four women had a personal history of anxiety, compared to one out of fifteen men. Thus, continuing with the theme that mental health experience is associated with mental health literacy, women may be more adept at identifying internalizing symptoms due to increased rates of personal experience. 
Although reported problem severity for the anxiety vignette did not differ between male and female participants, participants with more male children tended to report lower levels of problem severity. Considering that male children exhibit lower rates of internalizing disorders than female (Merikangas et al., 2009), having multiple boys at home may decrease parents' attunement to symptoms of anxiety. Additionally, these parents may experience an anchoring effect (Tversky \& Kahneman, 1974), wherein their baseline assessment of internalizing symptom severity is lower than other parents' due to inexperience with child anxiety. However, conclusions about the effect of child gender on parent perceptions are limited by the current study's design, as there is no way to ascertain how many of our participants' male versus female children have an anxiety disorder. Further exploration beyond the scope of this study is needed to test these hypotheses.

Gender also played a role in parents' perceptions of the ADHD vignette. Participants rated problem severity as more severe when the character was male versus female. Of note, the only differences between the two vignettes were the child's name and gender pronouns; all other descriptions of the child's personality and behavior were held constant. Therefore, the difference in reports of problem severity can solely be attributed to gender bias.

Studies show that parents tend to report a higher prevalence of externalizing symptoms among boys than girls (Nelson et al., 2013; Quinn \& Wigal, 2004); thus, they may be more attuned to ADHD symptoms when primed to think about boys rather than girls. That said, rates of problem recognition and perceived need for services were identical for male and female characters in our sample. Maniadaki and 
colleagues (2005) found that parents over-attribute intentionality of problem behaviors to boys with ADHD compared to girls with ADHD. Therefore, these findings suggest that parents recognize the same symptoms of ADHD in boys and girls but overestimate level of impairment in boys.

\section{Problem Type}

In contrast with the literature, parents in our study more often recognized symptoms of anxiety than symptoms of ADHD as indicative of a significant mental health problem. Past studies have found that parents more readily identify externalizing symptoms than internalizing symptoms, arguably due to increased visibility of externalizing problems (e.g., Teagle, 2002; Thurston et al., 2015). However, our findings robustly demonstrated that mental health experience contributed positively to problem recognition, and our population evidenced significantly higher rates of experience with anxiety than ADHD. Thus, participants may have been better able to relate to the descriptions of anxiety than ADHD and recognize them as indicative of a mental health problem.

\section{Additional Findings}

Several unanticipated findings emerged across analyses. Each will be discussed separately in the sections below.

Ethnicity. The only significant findings related to race and ethnicity showed a tendency for Hispanic/Latino participants to over-endorse problem severity and need for services in the non-clinical vignette. This finding is surprising, considering that Hispanic and Latino parents tend to recognize mental health problems at lower rates than other race and ethnic groups (Roberts et al., 2005). 
However, the specific struggles described in the typically developing child vignette may be perceived differently by Hispanic and Latino parents compared to non-Hispanic parents. For example, the vignette describes a child who occasionally gets into arguments with friends, yells, and slams doors. In a study of cultural variations in parenting by Julian and colleagues (1994), Hispanic parents evidenced greater emphasis on self-control than parents of other racial or ethnic backgrounds. Thus, while some parents may have interpreted this behavior to be relatively innocuous or developmentally normative, Hispanic parents may have been more prone to see the behavior as evidence of compromised self-restraint, thus increasing their ratings of problem severity.

Stepparents. Stepparents were more likely to identify a problem in the typically developing child vignette compared to non-stepparents. However, the small sample size of stepparents $(N=12)$ may have resulted in spurious findings. As parentchild relationship types go beyond the scope of the current study, future research is needed to tease apart the effects of identifying as a stepparent on problem recognition skills.

Students. Participants who were students at the time of data collection rated problem severity lower in the ADHD vignette than non-students. Considering the high levels of attention required for academic tasks such as listening to lectures, reading extensive texts, and test-taking, students may be inclined to normalize issues related to attention as a sign of fatigue or burn-out rather than an underlying psychological issue. However, as the current study did not focus on the student population, future research is needed to address the role of academia in perceptions of problem severity. 
Social Workers. Contrary to our hypothesis, those who viewed the intervention did not recommend mental health specialists more often than participants in the control group for either the anxiety or ADHD vignette. Due to the relatively high base rate of recommending mental health services, the effectiveness of the intervention to further raise awareness of the benefits of specialty mental health providers may have been limited. The intervention did, however, influence the rate at which participants recommended use of a social worker. In both the anxiety and ADHD vignettes, participants in the intervention condition were significantly more likely to recommend social workers than those in the control group. This finding is unexpected, as the pamphlet did not mention the social work profession, but rather described "mental health professionals" as a helpful resource for problem behaviors.

A review of the literature shows that the general public does tend to equate social workers with mental health treatment. In a nationwide study of social work perceptions, $57 \%$ of participants believed that social workers can provide mental health therapy. More specifically, nearly $90 \%$ believed that social workers "serve troubled children" (LeCroy \& Stinson, 2004). If participants in our study shared these beliefs, then the prompt in the intervention to consider a "mental health professional" may have encouraged increased endorsement of a social worker as an appropriate provider for children's mental health issues.

\section{Limitations}

Although this study benefits from its randomized controlled trial design, there are several limitations to note. First of all, the demographics of the sample are considerably limited with regard to race, gender, and socioeconomic status. Female 
participants significantly outnumbered men, though this likely reflects the greater tendency for women to identify as the primary caregiver (Family Caregiver Alliance, 2016). Furthermore, our sample was highly educated compared to the national average and tended to have high household incomes (U.S. Census Bureau, n.d.). Although Hispanic/Latinos, Asian Americans, and Native Americans were well-represented compared to U.S. census data (U.S. Census Bureau, 2010), White participants were over-represented and Black participants were under-represented. That said, Thurston and colleagues (2015) specifically compared problem recognition and perceived need for services between Black and White participants and found no effect of ethnicity. Still, findings from the current study cannot be reliably generalized across gender, racial, or socioeconomic groups.

The recruitment strategy may have contributed to the non-representative sample. In addition to recruiting from public schools, community centers, and literacy programs, social networks and snowball methods were used to increase the possible participant pool. Though this technique has garnered positive feedback in the statistical community, limitations can occur if participants only share recruitment materials with people of similar backgrounds (Waters, 2015).

Additionally, while collecting all data online likely allowed for a greater geographical range of participation, rates of Internet access may differ across racial and socioeconomic groups. For example, lower Internet access has been found among people with lower education and income, people from rural areas, and both Hispanic and non-Hispanic Black households (U.S. National Telecommunications \& Information Administration, 2010; File \& Ryan, 2014). Thus, using an online survey 
may have limited demographic diversity of the study sample. The study design further limited participation to literate, English-speaking individuals.

It is important to note that there may have been an aspect of self-selection in our sample. Our recruitment efforts explained the study to potential participants as an exploration of parents' responses to children's problem behaviors. Parents already interested in, and perhaps already knowledgeable about, children's mental health issues may have been more inclined to participate, which may have inflated problem recognition rates.

The intervention used was created for the use of the current study. Though it was created in consultation with a licensed clinical child psychologist using information echoed across child psychology informational web sites, it was not a validated psychoeducational tool. Additionally, the Flesch-Kincaid readability test (Kincaid et al., 1975) revealed that though the pamphlet was relatively easy to read, the language used corresponded to a 9.2 grade level. Those who completed the intervention agreed that it was very easy to understand, but it is possible that some participants who had more difficulty understanding the material dropped out of the study or failed the screener questions.

The vignettes themselves are also worthy of discussion. Though vignettes are often used in problem recognition studies (e.g., Loades \& Mastroyannopoulou, 2010; Jacobs \& Loades, 2016, Thurston et al., 2015), there is concern of low ecological validity. Considering the brevity of the vignettes, character descriptions may be a bit reductionistic. Particularly important to note is that each clinical vignette focuses on one mental health condition and describes relatively unambiguous symptoms. In 
reality, symptom presentation can vary tremendously, and comorbidity is quite common across child psychopathology, in part due to symptom overlap and in part due to shared risk factors across disorders (see Drabick \& Kendall, 2011).

Additionally, all of the vignettes feature a 10-year-old child, so it was not possible to assess problem recognition across developmental stages. The vignettes also do not address the ethnicity of the child. Although described symptoms were written to map onto DSM-IV disorders, symptom presentation varies across cultures. For example, Latino/Hispanic children tend to exhibit more somatic than emotional symptoms of anxiety compared to non-Hispanic White children (Koss, 1990). Future research would benefit from using vignettes that vary ethnic labels to assess for problem recognition bias, and that vary symptom presentation to assess for patterns of problem recognition across participants' cultural backgrounds.

Understanding problem recognition is also limited by the uniformity of problem severity across vignettes. In an assessment of anxiety problem recognition, Paulus and colleagues (2015) used vignettes featuring three levels of symptom severity: mild, moderate, and severe. Their findings show that participants underrated symptom severity compared to clinicians when reading the mild and moderate iterations of the vignette, but participants overrated problem severity compared to clinicians when symptoms were severe. Replicating the current study while varying symptom severity would allow for a more detailed analysis of parents' problem recognition process. 


\section{Clinical Implications and Future Directions}

Previous experience with mental health issues emerged as the most consistent and robust predictor of increased parental problem recognition and willingness to seek treatment for both internalizing and externalizing problem behaviors. Those who have previously navigated mental health issues and the mental health service sector likely have greater mental health literacy, meaning they may have a stronger understanding of what mental health problems look like and at what point intervention is merited.

The fact that parents without such exposure had a harder time recognizing mental health problems supports the intention of the current study to establish a reliable method of increasing parents' mental health literacy. Previous studies have found that parenting groups and workshops are effective mechanisms to increase their understanding and recognition of children's mental health problems (e.g., Umpierre et al., 2015; Harrison et al., 2016). However, the parents that are most in need of this knowledge are likely the same parents who would be unwilling to invest the time and effort required of these interventions. Chacko and colleagues (2017) found that parents of children with significant externalizing symptoms did not bring them to treatment if they did not see the relevance of therapy. Parents who are in denial about the signs and impact of mental health issues would likely benefit the most from increased mental health literacy, yet may be the hardest to engage.

The goal of the current study was to assess the effectiveness of a less involved method of intervention that may appeal to parents with low levels of mental health literacy. Craven and colleagues (2005) found that patients frequently take pamphlets about mental healthcare that are disseminated in family physicians' waiting and 
examining rooms, suggesting that such pamphlets achieve high readership.

Unfortunately, the pamphlet used in the current study did not give rise to noticeable improvements in mental health literacy.

It is important to note that the study sample did appear to have particularly high mental health literacy at baseline, likely due to self-selection. Future research may benefit from a second trial of this intervention with a more representative sample, or even a targeted sample of parents with low mental health literacy. Furthermore, the vignettes and follow-up questions themselves may have primed parents to consider children's problems through a mental health lens. Future research would benefit from including a pre- and post-assessment of mental health literacy to identify whether differences over time can be attributed to the intervention.

Despite the promise of cost-effectiveness and high scalability, there are several limitations of brief, written psychoeducation that are worthy of consideration. While brevity may encourage greater readership, it also limits the depth of information that can be provided. Additionally, written materials may be too passive to make a significant impact. On the other hand, time-consuming educational groups or workshops that require interest and engagement are unlikely to attract a demographic that currently exhibits low levels of interest and engagement in mental health issues. Multiple methods of intervention have yet to be assessed in a single study; thus, future research may benefit from comparing the effects of written interventions of varying lengths, or written content versus video content, or even written content versus an inperson workshop or seminar. 
Considering the pervasive tendency to normalize problematic behavior, a more effective way to engage parents who are unaware of or in denial about their child's symptoms may be to involve resources that parents already use to learn about child development. Our study demonstrated that parents overwhelmingly trust pediatricians for guidance, more so than families, friends, teachers, or mental health specialists. This finding parallels other studies showing that parents tend to consult primary care physicians with concerns about problem behaviors and child development (Brown et al., 2014; Sayal et al., 2015; MacNaughton \& Rodrigue, 2001).

Parents typically have an ongoing relationship with a pediatrician and view the primary care office as the first stop for behavioral and developmental concerns (Nasir et al., 2016). Anxiety, due to somatic symptoms, and ADHD, due to high visibility, are often diagnosed by a primary care physician (see Ramsawh et al., 2010; Visser et al., 2015). However, although many mental and behavioral health issues are managed exclusively or adjunctively by pediatricians, primary care doctors generally exhibit poor identification of these conditions, report feeling undertrained in the mental and behavioral health arena, and endorse logistic constraints regarding ongoing treatment (Glascoe \& Marks, 2011; Zwaanswijk et al., 2003; Marie-Mitchell et al., 2016; Thielke et al., 2007; Brahmbatt et al., 2016).

Fortunately, as healthcare practices become more integrated and multidisciplinary, psychologists have a greater presence than ever in medical centers through co-located offices, patient-centered medical homes, and other collaborative care settings (de Voursney \& Huang, 2016). Integrating into the primary healthcare sector may reduce stigma and increase treatment adherence, as parents may see 
collaborative healthcare facilities as a “one-stop shop" for their children's needs. Additionally, psychologists have more opportunities to engage families attending well-care visits in appropriate diagnostic assessments and subsequent treatment (Kazak et al., 2017; Asarnow et al., 2017).

If equipped with more accurate expectations and understanding of normative behavior in children, parents can be empowered to identify next steps to managing problem behavior. Future research may benefit from utilizing collaborative care environments to explore opportunities for parental engagement and education. For example, psychologists can use the waiting room to prime parents with the knowledge, language, and perspective on children's mental health to recognize concerns and be informed self-advocates. Pediatricians can be trained to provide parents with more information about developmentally appropriate behavior. Medical centers can pilot consultation models to see if having a co-located or readily available psychologist increases parents' openness to mental health services. Future studies should also consider including a long-term follow-up component to identify any latent effects of psychoeducation on mental health literacy. The research to date on improving parent problem recognition is quite limited, but the opportunities for experimentation and discovery are plentiful. 


\section{Tables}

Table 1. Descriptive Statistics for Problem Severity

\begin{tabular}{llllll}
\hline Vignette & $M(S D)$ & Skewness & Kurtosis & Variance & Observed Range \\
\hline Anxiety & $14.84(2.31)$ & -.37 & .79 & 5.32 & 7 to 20 \\
ADHD & $14.70(2.54)$ & -.13 & .070 & 6.46 & 7 to 20 \\
TDC & $7.60(2.81)$ & .90 & .47 & 7.88 & 4 to 16 \\
\hline Note. $N=298 . \mathrm{M}=$ Mean. SD = Standard Deviation. ADHD = Attention- \\
Deficit/Hyperactivity Disorder. TDC = Typically developing child.
\end{tabular}


Table 2. Demographic Characteristics of Participants

\begin{tabular}{|c|c|c|c|c|}
\hline \multirow[b]{2}{*}{ Variable } & \multicolumn{2}{|c|}{ Groups } & \multirow[b]{2}{*}{ Difference } & \multirow[b]{2}{*}{$p$} \\
\hline & $\begin{array}{l}\text { Intervention } \\
(N=123)\end{array}$ & $\begin{array}{l}\text { Control } \\
(N=175)\end{array}$ & & \\
\hline \multicolumn{5}{|l|}{ Participant Gender } \\
\hline Male & $13(10.57 \%)$ & $18(10.29 \%)$ & & \\
\hline Female & $110(89.43 \%)$ & $157(89.71 \%)$ & $\chi^{2}(1)=.006$ & n.s. \\
\hline Participant Mean Age $(S D)$ & $40.99(6.86)$ & $40.66(7.07)$ & $t(295)=-.399$ & n.s. \\
\hline \multicolumn{5}{|l|}{ Participant Ethnicity } \\
\hline Hispanic/Latino & $12(9.76 \%)$ & $26(14.86 \%)$ & & \\
\hline Non-Hispanic/Latino & $109(88.62 \%)$ & $146(83.43 \%)$ & $\chi^{2}(1)=1.70$ & n.s. \\
\hline \multicolumn{5}{|l|}{ Participant Race } \\
\hline White/Caucasian & $108(87.80 \%)$ & $160(91.43 \%)$ & $\chi^{2}(1)=1.05$ & n.s. \\
\hline Asian & $5(4.07 \%)$ & $2(1.14 \%)$ & $\chi^{2}(1)=2.69$ & n.s. \\
\hline Black/African American & $1(.81 \%)$ & $4(2.29 \%)$ & $\chi^{2}(1)=.95$ & n.s. \\
\hline $\begin{array}{l}\text { Native American/Alaska Native } \\
\text { Native Hawaiian/Pacific }\end{array}$ & $2(1.63 \%)$ & $2(1.14 \%)$ & $\chi^{2}(1)=.13$ & n.s. \\
\hline Islander & - & - & - & - \\
\hline Other & $7(5.69 \%)$ & $8(4.57 \%)$ & $\chi^{2}(1)=.19$ & n.s. \\
\hline \multicolumn{5}{|l|}{ Marital Status } \\
\hline Single & $7(5.69 \%)$ & $8(4.57 \%)$ & & \\
\hline $\begin{array}{l}\text { Married/domestic } \\
\text { partnership }\end{array}$ & $107(86.99 \%)$ & $154(88.00 \%)$ & & \\
\hline Divorced & $6(4.88 \%)$ & $9(5.14 \%)$ & & \\
\hline Separated & $2(1.63 \%)$ & $4(2.29 \%)$ & & \\
\hline Widowed & $1(.81 \%)$ & - & $\chi^{2}(1)=1.78$ & n.s. \\
\hline \multicolumn{5}{|l|}{$\begin{array}{l}\text { Participant Highest Degree of } \\
\text { Education }\end{array}$} \\
\hline Less than high school & $1(.81 \%)$ & - & & \\
\hline $\begin{array}{l}\text { High school graduate (incl. } \\
\text { equivalency) }\end{array}$ & $2(1.63 \%)$ & $10(5.71 \%)$ & & \\
\hline Some college, no degree & $14(11.38 \%)$ & $20(11.43 \%)$ & & \\
\hline Associate's degree & $5(4.07 \%)$ & $13(7.43 \%)$ & & \\
\hline Bachelor's degree & $40(32.52 \%)$ & $55(31.43 \%)$ & & \\
\hline $\begin{array}{l}\text { Graduate or professional } \\
\text { degree }\end{array}$ & $61(49.59 \%)$ & $77(44.00 \%)$ & $\chi^{2}(5)=6.29$ & n.s. \\
\hline Currently a Student (\%) & $14(11.38 \%)$ & $20(11.43 \%)$ & $\chi^{2}(1)<.001$ & n.s. \\
\hline
\end{tabular}

Note. SD = Standard Deviation. n.s. = Not Significant.

$*$ Significant at the $\alpha=.05$ level 
Table 2. Demographic Characteristics of Participants (continued)

\begin{tabular}{|c|c|c|c|c|}
\hline \multirow[b]{2}{*}{ Variable } & \multicolumn{2}{|c|}{ Groups } & \multirow[b]{2}{*}{ Difference } & \multirow[b]{2}{*}{$P$} \\
\hline & $\begin{array}{l}\text { Intervention } \\
(N=123)\end{array}$ & $\begin{array}{l}\text { Control } \\
(N=175)\end{array}$ & & \\
\hline \multicolumn{5}{|l|}{ Participant Employment Status } \\
\hline Work full-time (35+ hours) & $68(55.28 \%)$ & $107(61.14 \%)$ & & \\
\hline Work part-time ( $<35$ hours) & $25(20.33 \%)$ & $32(18.29 \%)$ & & \\
\hline $\begin{array}{l}\text { Not working but seeking } \\
\text { employment }\end{array}$ & 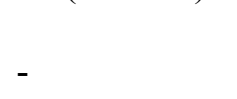 & $2(1.14 \%)$ & & \\
\hline $\begin{array}{l}\text { Not working, not seeking } \\
\text { employment }\end{array}$ & $23(18.70 \%)$ & $27(15.43 \%)$ & & \\
\hline Other & $7(5.69 \%)$ & $7(4.00 \%)$ & $\chi^{2}(4)=2.89$ & n.s. \\
\hline Works part-time & $4(3.25 \%)$ & $7(4.00 \%)$ & & \\
\hline $\begin{array}{l}\text { Not working but seeking } \\
\text { employment }\end{array}$ & $6(4.88 \%)$ & $4(2.29 \%)$ & & \\
\hline $\begin{array}{l}\text { Not working, not seeking } \\
\text { employment }\end{array}$ & $5(4.07 \%)$ & $6(3.43 \%)$ & & \\
\hline Other & $4(3.25 \%)$ & $6(3.43 \%)$ & $\chi^{2}(6)=4.62$ & n.s. \\
\hline \multicolumn{5}{|l|}{ Household Annual Income } \\
\hline$<\$ 16,000$ & $1(.81 \%)$ & $3(1.71 \%)$ & & \\
\hline$\$ 16,000-\$ 24,999$ & $6(4.88 \%)$ & $2(1.14 \%)$ & & \\
\hline$\$ 25,000-\$ 49,999$ & $7(5.69 \%)$ & $13(7.43 \%)$ & & \\
\hline$\$ 50,000-\$ 99,999$ & $28(22.76 \%)$ & $44(25.29 \%)$ & & \\
\hline$\$ 100,000-\$ 149,999$ & $23(18.70 \%)$ & $42(24.00 \%)$ & & \\
\hline$\geq \$ 150,000$ & $57(46.34 \%)$ & $68(38.86 \%)$ & $\chi^{2}(5)=6.56$ & n.s. \\
\hline Mean Number of Children $(S D)$ & $2.35(1.00)$ & $2.23(.91)$ & $\mathrm{t}(296)=-1.09$ & n.s. \\
\hline $\begin{array}{l}\text { Mean Number of Children Living } \\
\text { in the Home }(S D)\end{array}$ & $2.13(.86)$ & $2.06(.90)$ & $\mathrm{t}(296)=.70$ & n.s. \\
\hline $\begin{array}{l}\text { Mean Number of Children by } \\
\text { Gender }(S D)\end{array}$ & & & & \\
\hline Male & $1.54(.80)$ & $1.50(.80)$ & $\mathrm{t}(234)=-.40$ & n.s. \\
\hline Female & $1.59(.83)$ & $1.34(.66)$ & $t(156)=-2.45$ & $.016^{*}$ \\
\hline \multicolumn{5}{|l|}{$\begin{array}{l}\text { Participant's Relationship to } \\
\text { Child/Children }\end{array}$} \\
\hline Biological parent & $116(94.31 \%)$ & $170(97.14 \%)$ & $\chi^{2}(1)=1.50$ & n.s. \\
\hline Adoptive parent & $7(5.69 \%)$ & $6(3.43 \%)$ & $\chi^{2}(1)=.89$ & n.s. \\
\hline Step-parent & $5(4.07 \%)$ & $7(4.00 \%)$ & $\chi^{2}(1)=.001$ & n.s. \\
\hline Foster parent & $1(.81 \%)$ & $3(1.71 \%)$ & $\chi^{2}(1)=.44$ & n.s. \\
\hline Grandparent & - & $1(.57 \%)$ & $\chi^{2}(1)=.71$ & n.s. \\
\hline Other & $3(2.44 \%)$ & $3(1.71 \%)$ & $\chi^{2}(1)=.19$ & n.s. \\
\hline
\end{tabular}

Note. SD $=$ Standard Deviation. n.s. $=$ Not Significant.

$*$ Significant at the $\alpha=.05$ level 
Table 3. Rate of Problem

\begin{tabular}{|c|c|}
\hline \multicolumn{2}{|c|}{ Recognition in the Anxiety Vignette } \\
\hline Variable & $\%$ \\
\hline \multicolumn{2}{|c|}{ Experimental Group } \\
\hline Control & 62.9 \\
\hline Intervention & 61.0 \\
\hline \multicolumn{2}{|c|}{ Mental Health Experience } \\
\hline No & 47.9 \\
\hline Yes & 74.7 \\
\hline \multicolumn{2}{|c|}{ Character Gender } \\
\hline Male & 61.9 \\
\hline Female & 62.3 \\
\hline Total & 62.1 \\
\hline
\end{tabular}

Table 4. Rate of Problem

Recognition in the ADHD Vignette

\begin{tabular}{lc}
\hline Variable & $\%$ \\
\hline Experimental Group & \\
$\quad$ Control & 53.1 \\
$\quad$ Intervention & 57.7 \\
Mental Health Experience & \\
$\quad$ No & 43.6 \\
Yes & 65.2 \\
Character Gender & \\
$\quad$ Male & 58.7 \\
$\quad$ Female & 51.4 \\
\hline Total & 55.0 \\
\hline
\end{tabular}

Note. $N=298$. ADHD = Attention-Deficit/Hyperactivity Disorder.

Table 5. Rate of Problem

Recognition in the TDC Vignette

\begin{tabular}{ll}
\hline Variable & $\%$ \\
\hline Experimental Group & \\
Control & 5.7 \\
$\quad$ Intervention & 4.1 \\
Mental Health Experience & \\
$\quad$ No & 2.9 \\
$\quad$ Yes & 7.0 \\
Character Gender & \\
$\quad$ Male & 6.1 \\
Female & 4.0 \\
\hline Total & 5.0 \\
\hline Note.
\end{tabular}

Note. $N=298$. TDC $=$ Typically Developing Child. 
Table 6. Logistic Regression Predicting Problem Recognition in the Anxiety Vignette

\begin{tabular}{llllll}
\hline Predictor & $\beta$ & Wald $\chi^{2}$ & $p$ & Odds Ratio & 95\% CI of Odds Ratio \\
\hline Condition & .04 & .022 & .88 & 1.04 & {$[.62,1.76]$} \\
Mental Health & & & & & \\
$\quad$ Experience & 1.15 & 19.26 & $<.001$ & 3.16 & {$[1.89,5.27]$} \\
Character Gender & -.15 & .32 & .57 & .86 & {$[.51,1.45]$} \\
Participant Gender & 1.21 & 8.26 & .004 & 3.36 & {$[1.47,7.68]$} \\
Hispanic/Latino & -.69 & 2.65 & .10 & .50 & {$[.22,1.15]$} \\
White/Caucasian & .60 & 1.32 & .25 & 1.82 & {$[.66,5.04]$} \\
Asian & -1.80 & 2.33 & .13 & .17 & {$[.016,1.67]$} \\
\hline
\end{tabular}

Note. $N=298 . \beta=$ Unstandardized coefficients. $\mathrm{CI}=$ Confidence Interval.

Table 7. Logistic Regression Predicting Problem Recognition in the ADHD Vignette

\begin{tabular}{llllll}
\hline Predictor & $\beta$ & Wald $\chi^{2}$ & $p$ & Odds Ratio & $95 \%$ CI of Odds Ratio \\
\hline Condition & .23 & .86 & .35 & 1.25 & {$[.78,2.02]$} \\
Mental Health & & & & & \\
$\quad$ Experience & .89 & 13.68 & $<.001$ & 2.43 & {$[1.52,3.88]$} \\
Character Gender & -.29 & 1.49 & .22 & .75 & {$[.47,1.19]$} \\
\hline
\end{tabular}

Note. $N=298 . \beta=$ Unstandardized coefficients. $\mathrm{CI}=$ Confidence Interval. $\mathrm{ADHD}=$ Attention-Deficit/Hyperactivity Disorder.

Table 8. Logistic Regression Predicting Problem Recognition in the TDC Vignette

\begin{tabular}{llllll}
\hline Predictor & $\beta$ & Wald $\chi^{2}$ & $p$ & Odds Ratio & 95\% CI of Odds Ratio \\
\hline Condition & -.38 & .43 & .51 & .69 & {$[.22,2.1]$} \\
Mental Health & & & & & \\
$\quad$ Experience & .77 & 1.59 & .21 & 2.16 & {$[.65,7.17]$} \\
Character Gender & -.53 & .90 & .34 & .59 & {$[.20,1.76]$} \\
Step-Parent & 1.85 & 6.10 & .014 & 6.37 & {$[1.47,27.69]$} \\
\hline
\end{tabular}

Note. $N=298 . \beta=$ Unstandardized coefficients. $\mathrm{CI}=$ Confidence Interval. $\mathrm{TDC}=$ Typically Developing Child. 
Table 9. Rate of Perceived Need for Services in the Anxiety Vignette

\begin{tabular}{ll}
\hline Variable & $\%$ \\
\hline Experimental Group & \\
$\quad$ Control & 91.4 \\
$\quad$ Intervention & 87.8 \\
Mental Health Experience & \\
$\quad$ No & 85.7 \\
$\quad$ Yes & 93.7 \\
Character Gender & \\
$\quad$ Male & 89.8 \\
$\quad$ Female & 90.1 \\
\hline Total & 89.9 \\
\hline Note. $N=298$. &
\end{tabular}

Table 10. Rate of Perceived Need for Services in the ADHD Vignette

\begin{tabular}{lc}
\hline Variable & $\%$ \\
\hline Experimental Group & \\
Control & 89.1 \\
Intervention & 90.2 \\
Mental Health Experience & \\
No & 82.9 \\
Yes & 95.6 \\
Character Gender & \\
Male & 90.7 \\
Female & 88.5 \\
\hline Total & 89.6 \\
\hline
\end{tabular}

Note. $N=298$. ADHD = Attention-Deficit/Hyperactivity Disorder.

Table 11. Rate of Perceived Need for Services in the TDC Vignette

\begin{tabular}{ll}
\hline Variable & $\%$ \\
\hline Experimental Group & \\
Control & 14.9 \\
Intervention & 12.2 \\
Mental Health Experience & \\
No & 11.4 \\
Yes & 15.8 \\
Character Gender & \\
$\quad$ Male & 15.6 \\
Female & 11.9 \\
\hline Total & 13.8 \\
\hline Note.
\end{tabular}

Note. $N=298$. TDC $=$ Typically Developing Child. 
Table 12. Logistic Regression Predicting Perceived Need for Services in the Anxiety Vignette

\begin{tabular}{llllll}
\hline Predictor & $\beta$ & Wald $^{2}$ & $p$ & Odds Ratio & 95\% CI of Odds Ratio \\
\hline Condition & -.38 & 0.89 & .35 & .69 & {$[.31,1.5]$} \\
Mental Health & & & & & \\
$\quad$ Experience & .85 & 4.20 & .04 & 2.34 & {$[1.04,5.29]$} \\
Character Gender & -.26 & 0.40 & .53 & .77 & {$[.34,1.73]$} \\
Participant Gender & 1.61 & 10.98 & .001 & 4.98 & {$[1.93,12.85]$} \\
\hline
\end{tabular}

Note. $N=298 . \beta=$ Unstandardized coefficients. $\mathrm{CI}=$ Confidence Interval.

Table 13. Logistic Regression Predicting Perceived Need for Services in the ADHD Vignette

\begin{tabular}{llllll}
\hline Predictor & $\beta$ & Wald $^{2}$ & $p$ & Odds Ratio & 95\% CI of Odds Ratio \\
\hline Condition & .26 & .39 & .54 & 1.29 & {$[.58,2.89]$} \\
Mental Health & & & & & \\
$\quad$ Experience & 1.61 & 11.40 & .001 & 4.98 & {$[1.96,12.66]$} \\
Character Gender & -.11 & .081 & .78 & 0.89 & {$[.41,1.95]$} \\
Age & .05 & 3.00 & .084 & 1.06 & {$[.99,1.12]$} \\
\hline
\end{tabular}

Note. $N=298 . \beta=$ Unstandardized coefficients. $\mathrm{CI}=$ Confidence Interval. $\mathrm{ADHD}=$ Attention-Deficit/Hyperactivity Disorder.

Table 14. Logistic Regression Predicting Perceived Need for Services in the TDC Vignette

\begin{tabular}{llllll}
\hline Predictor & $\beta$ & Wald $\chi^{2}$ & $p$ & Odds Ratio & 95\% CI of Odds Ratio \\
\hline Condition & -.19 & .27 & .60 & .83 & {$[.41,1.69]$} \\
Mental Health & & & & & \\
$\quad$ Experience & .37 & 1.06 & .30 & 1.44 & {$[.72,2.89]$} \\
Character Gender & -.35 & .97 & .32 & .71 & {$[.35,1.41]$} \\
Hispanic/Latino & .89 & 3.59 & .058 & 2.44 & {$[.97,6.16]$} \\
White/Caucasian & -.41 & .37 & .54 & .66 & {$[.18,2.50]$} \\
Race: "Other" & .46 & .33 & .57 & 1.58 & {$[.33,7.57]$} \\
\hline
\end{tabular}

Note. $N=298 . \beta=$ Unstandardized coefficients. $\mathrm{CI}=$ Confidence Interval. $\mathrm{TDC}=$ Typically Developing Child. 
Table 15. Service Recommendations by Vignette

\begin{tabular}{lccc}
\hline $\begin{array}{l}\text { Type of } \\
\text { Service/Provider }\end{array}$ & $\begin{array}{c}\text { \% Recommended for } \\
\text { Anxiety Vignette }\end{array}$ & $\begin{array}{c}\% \text { Recommended for } \\
\text { ADHD Vignette }\end{array}$ & $\begin{array}{c}\text { \%ecommended for } \\
\text { TDC Vignette }\end{array}$ \\
\hline Psychologist & 72.8 & 61.7 & 9.1 \\
Guidance Counselor & 55 & 53 & 7 \\
PCP & 43.6 & 57.4 & 3.4 \\
Teacher & 43 & 47.7 & 5.4 \\
Family & 30.9 & 28.5 & 6.7 \\
Internet/Book & 27.9 & 25.2 & 6.7 \\
Friends & 25.2 & 21.5 & 5.4 \\
Psychiatrist & 11.4 & 13.1 & 0.7 \\
Social Worker & 10.7 & 11.4 & 0.7 \\
Support Group & 7.4 & 7 & 1.7 \\
Religious & 3.4 & 2.3 & - \\
Other & 2 & 2.7 & 0.3 \\
Crisis Hotline & 0.7 & 0.3 & - \\
Inpatient & 0.3 & 0.7 & - \\
\hline
\end{tabular}

Note. $N=298$. ADHD $=$ Attention-Deficit/Hyperactivity Disorder. TDC $=$ Typically Developing Child. PCP = Primary Care Provider. 
Table 16. Cross-Tabulation of Problem Recognition and Perceived Need for Services in the Anxiety Vignette.

\begin{tabular}{lccc}
\hline Problem & \multicolumn{2}{c}{ Perceived Need for Services } & \\
\cline { 2 - 3 } Recognition & No & Yes & $\chi^{2}$ \\
\hline No & 30 & 83 & $54.61^{* *}$ \\
Yes & 0 & 185 & \\
\hline $\begin{array}{l}\text { Note. } N=298 . \\
* *=p<.001 .\end{array}$ & & & \\
$*$
\end{tabular}

Table 17. Cross-Tabulation of Problem Recognition and Perceived Need for Services in the ADHD Vignette.

\begin{tabular}{lccc}
\hline Problem & \multicolumn{2}{c}{ Perceived Need for Services } & \\
\cline { 2 - 3 } Recognition & No & Yes & $\chi^{2}$ \\
\hline No & 31 & 103 & $42.35^{* *}$ \\
Yes & 0 & 164 & \\
\hline Note. $N=298$. & ADHD $=$ Attention-Deficit/Hyperactivity Disorder. \\
$* *=p<001$ & &
\end{tabular}

$* *=p<.001$.

Table 18. Sources Parents Use to Learn about Child Rearing and Child Development

\begin{tabular}{ll}
\hline Source & $\%$ \\
\hline Pediatrician/Primary Care Physician & $73.5 \%$ \\
Family & $67.8 \%$ \\
Books & $66.1 \%$ \\
Friends & $65.1 \%$ \\
Internet & $62.4 \%$ \\
Teacher & $35.6 \%$ \\
Psychologist/Counselor/Therapist & $24.8 \%$ \\
Guidance Counselor/School Psychologist & $21.5 \%$ \\
Videos & $14.8 \%$ \\
\hline
\end{tabular}

Note. $N=298$. 


\section{Figures}

Figure 1. Flow diagram of participants.

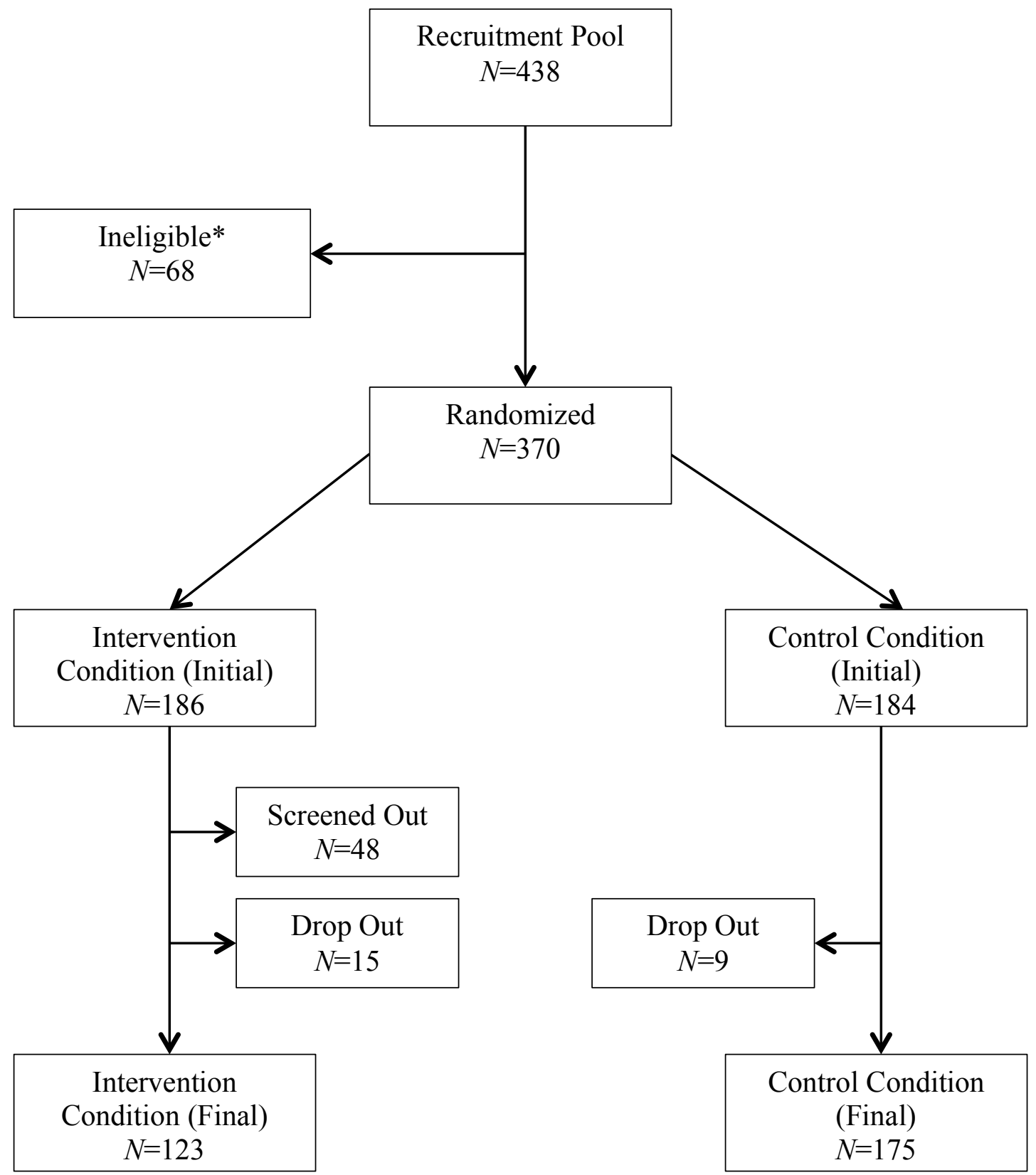

*Excluded from study based on failure to satisfy inclusion and/or exclusion criteria 
Figure 2.

\section{Predictors of Problem Severity in the ADHD Vignette}

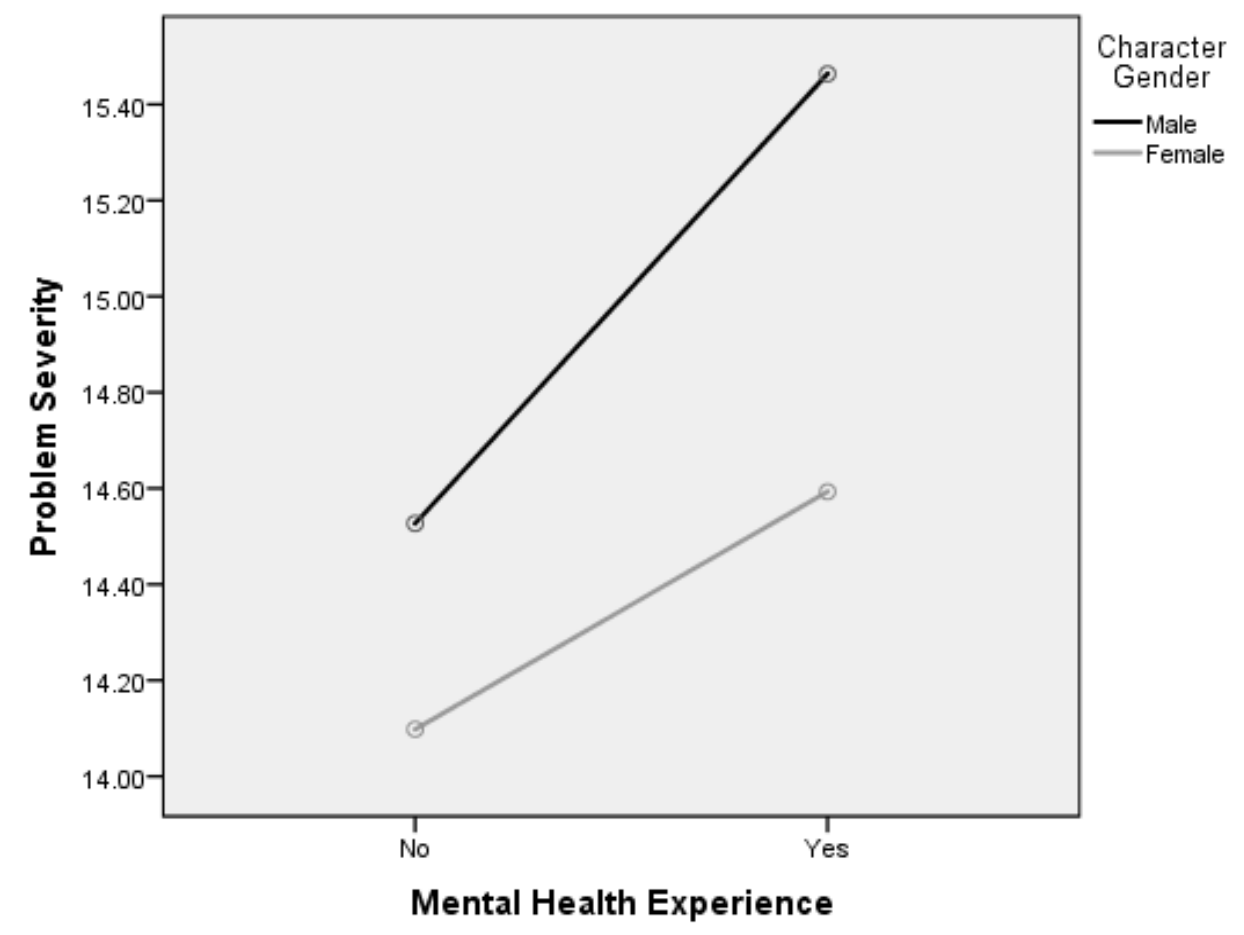

Covariates appearing in the model are evaluated at the following values: Are you currently a student? = 1.89 , How many children do you have $?=2.2785$, How many of those children live with you $?=2.0872$

Note. $N=298$. Problem Severity Range $=4$ to 20 . ADHD $=$ AttentionDeficit/Hyperactivity Disorder. 
Figure 3.

Predictors of Problem Severity in the TDC Vignette

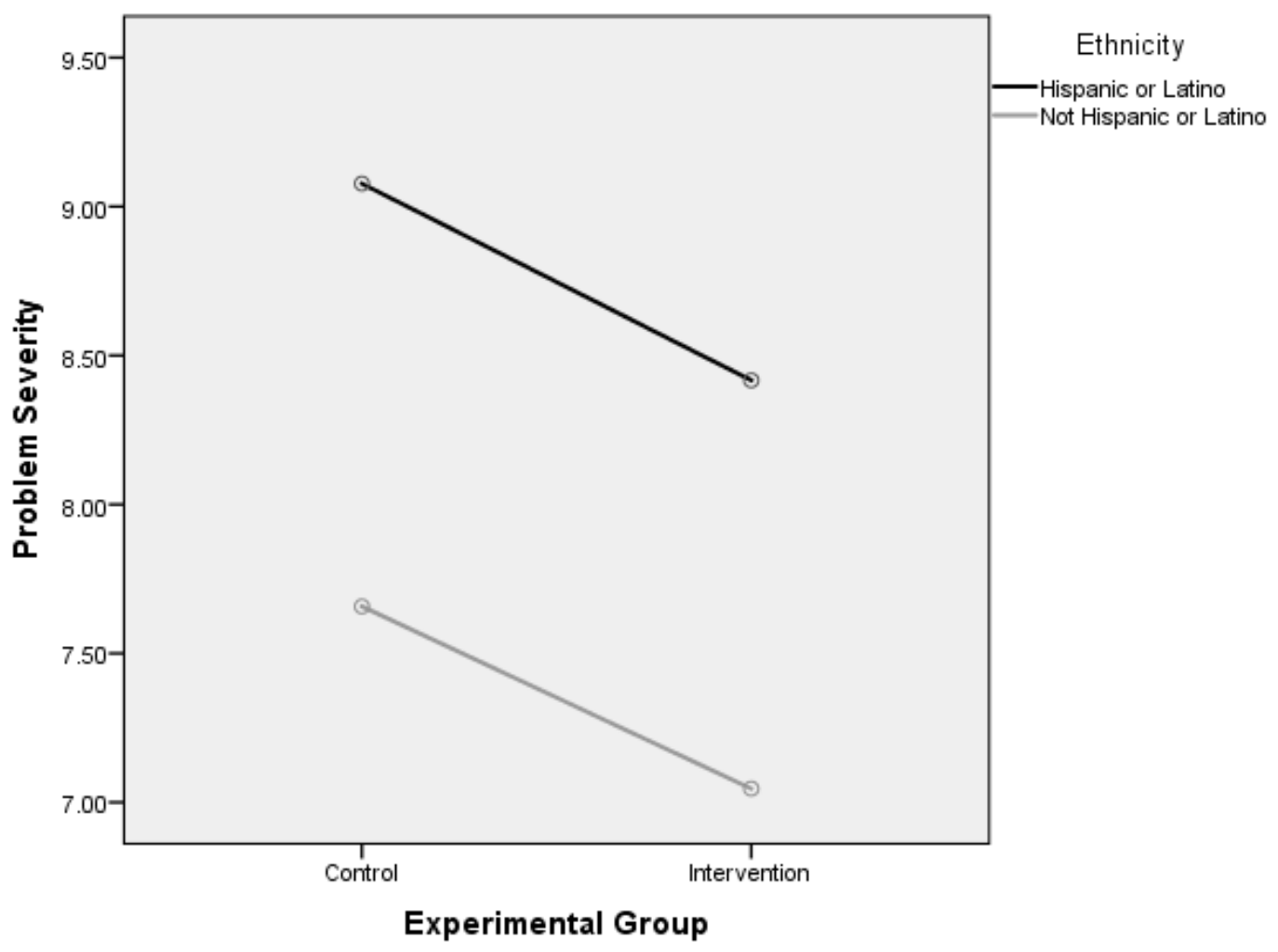

Note. $N=298$. Problem Severity Range $=4$ to 20 . TDC $=$ Typically Developing Child. 


\section{Appendices}

Appendix A. Demographics Form.

Please tell us the following information about yourself:

1. Age:

2. Gender: Male Female Other:

3. Ethnicity: Hispanic or Latino Not Hispanic or Latino

4. Race (Select all that apply)

White/Caucasian Black/African American

Asian Native Hawaiian/Pacific Islander

Native American/Alaska Native Other:

5. Marital status: Single, never married Married or domestic partnership

Widowed Divorced Separated

6. What is the highest degree or level of education you have completed?

Less than high school

Some college, no degree

Bachelor's degree
High school graduate (includes equivalency)

Associate's degree

Graduate or professional degree

7. What is your employment status?

Work full-time (35 hours or more) Work part-time (Less than 35 hours)

Student

Not working but seeking employment

Not working and not seeking employment Other:

8. If you have a partner living in the home, what is their employment status?

I do not have a partner living in the home

Work full-time (35 hours or more) Work part-time (Less than 35 hours)

Student

Not working but seeking employment

Not working and not seeking employment Other:

9. Household annual income:
Less than $\$ 16,000$
$\$ 16,000-\$ 24,999$
$\$ 25,000-\$ 50,000$
$\$ 50,000-\$ 99,999 \quad \$ 100,000-\$ 149,999$
$\$ 150,000$ or more 
10. How many children do you have?

11. How many of those children live with you?

12. How old are each of your children?

13. How many of your children are:

Male

Female

Other

14. Do you consider yourself a guardian or primary caregiver for your children?

Yes No

15. What is your relationship to your children? Select all that apply:

Biological Parent

Foster parent
Adoptive Parent

Grandparent
Stepparent

Other: 
Appendix B. Anxiety, ADHD, and TDC vignettes from Thurston and colleagues (2015).

\section{Please read the following vignette and answer the questions below:}

A. (Michael/Ashley) is a 10-year-old (boy/girl) who has been overly worried and nervous about various things at home and school for the past 6 months. Some of (his/her) worries include getting perfect grades at school, (his/her) performance on the soccer team, and keeping (his/her) room tidy. (Michael/Ashley) has also been experiencing some difficulty concentrating at school due to (his/her) worrying, and as a result (his/her) grades are beginning to fall. (He/She) is easily tired throughout the day and is unable to sleep at night. Recently, (Michael's/Ashley's) classmates have been making fun of (him/her). (He/She) realizes that (he/she) worries too much and wishes (he/she) could control it so (he/she) could be more like other children.

B. (Chris/Brittany) is a 10-year-old (boy/girl) who has become distracted easily and forgetful at home and school over the past 6 months. (He/She) often fails to finish (his/her) chores and school work and repeatedly makes careless mistakes on assignments. (Chris/Brittany) has difficulty paying attention for long periods of time and does not appear to listen when spoken to. (He/She) has a hard time waiting (his/her) turn, talks a lot, and often interrupts others when they are talking. (Chris/Brittany) usually has difficulty playing quietly. At school, (he/she) is out of (his/her) seat constantly and has become very fidgety. (Chris/Brittany) has always been an active child, but (his/her) recent 
behavior is now affecting (his/her) school work and ability to keep and make new friends.

C. (Joshua/Jessica) is a 10-year-old (boy/girl) who has been receiving A and B grades in school over the past 6 months. (He/she) has several friends at home and school who (he/she) enjoys spending time with. Although (he/she) usually gets along with most children, (Joshua/Jessica) sometimes gets into minor arguments with (his/her) friends when playing games or when (he/she) does not get (his/her) way. Occasionally, when (Joshua/Jessica) gets angry or upset, (he/she) yells or slams (his/her) door; however, once (he/she) cools down, (he/she) usually feels bad and apologizes for (his/her) behavior. (Joshua/Jessica) participates in several activities after school, such as soccer and reading club. 
Appendix C. Questionnaire regarding problem recognition, problem severity, and perceived need for services.

The following questions appeared after each vignette:

1. How seriously would you rate (insert child name)'s problems compared to other 10year-olds?

$\begin{array}{lllll}1 & 2 & 3 & 4 & 5\end{array}$

Not at all A little Somewhat Very Extremely

2. How concerned would you be about (insert child name)'s problems?

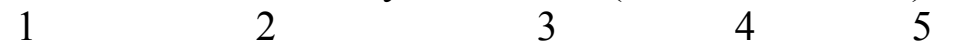

Not at all A little Somewhat Very Extremely

3. How much do you think these problems would affect (insert child name)'s daily activities?

$\begin{array}{ccccc}1 & 2 & 3 & 4 & 5 \\ \text { Not at all } & \text { A little } & \text { Somewhat } & \text { Very } & \text { Extremely }\end{array}$

4. How much do you think these problems would impact (insert child name)'s family? $\begin{array}{lllll}1 & 2 & 3 & 4 & 5\end{array}$

Not at all A little Somewhat Very Extremely

5. Do you think (insert child name) has a mental health problem? Yes No

6. If you were responsible for (insert child name), would you seek help for (him/her)? Yes No

7. Who would you most likely go to for help? Select all that apply:

Psychologist, Counselor, or Therapist

Psychiatrist or Psychiatric Nurse

Primary Care Physician or Other Medical Doctor

Inpatient Hospital or Day Program

Guidance Counselor or School Psychologist

Teacher or Other School Staff Member

Social Worker or Case Manager

Religious Leader

Crisis Hotline

Support Group

Family

Friends

I would search the Internet and/or read a book

Other: 
The following questions were asked once after all questions regarding vignettes have been completed:

8. If you had to guess, what percent of children in the U.S. do you think have mental health issues?

9. What percent of those children do you think get help?

10. What percent of the time do you think mental health therapy is helpful for kids with those issues? 
Appendix D. Questionnaire regarding experiences with mental health issues.

1. Do you have a personal history of mental health issues?

Yes No

If no to (1), skip to (2)

If yes to (1):

1a. What type of mental health issues? Select all that apply:

Anxiety Disorder

Depressive Disorder

ADHD

Oppositional Defiant Disorder

Autism Spectrum Disorder

Substance Use Problems

Posttraumatic Stress Disorder (PTSD)

Tic Disorder

Other:

1b. Was this problem formally diagnosed by a professional (e.g. therapist, doctor, psychiatric nurse, etc.)?

Yes No

1c. Did you seek help for this problem?

Yes No

If no to (1c), skip to (1e)

If yes to $(1 c)$ :

1d. Who did you go to for help? Select all that apply:

Psychologist, Counselor, or Therapist

Psychiatrist or Psychiatric Nurse

Primary Care Physician or Other Medical Doctor

Inpatient Hospital or Day Program

Guidance Counselor or School Psychologist

Teacher or Other School Staff Member

Social Worker or Case Manager

Religious Leader

Crisis Hotline

Support Group

Family

Friends

I searched the Internet and/or read a book

Other:

If yes to (1): 1e. How did you know you were having a mental health problem? 
If no to (1c), skip to (2)

If yes to $(1 c)$ :

1f. How did you know that you needed help for this problem?

1g. How did you decide where to go for help?

1h. Do you have any comments you would like to share about your experience of seeking help for this problem?

2. Do any of your children have a history of mental health issues?

Yes No

If no to (2), skip to (3)

If yes to (2):

2a. What type of mental health issues? Select all that apply:

Anxiety Disorder

Depressive Disorder

ADHD

Oppositional Defiant Disorder

Autism Spectrum Disorder

Substance Use Problems

Posttraumatic Stress Disorder (PTSD)

Tic Disorder

Other:

2b. Was this problem formally diagnosed by a professional (e.g., therapist, doctor, psychiatric nurse, etc.)?

Yes No

2c. Did you seek help for this problem?

Yes No

If yes to (2c):

2d. Who did you go to for help? Select all that apply:

Psychologist, Counselor, or Therapist

Psychiatrist or Psychiatric Nurse

Primary Care Physician or Other Medical Doctor

Inpatient Hospital or Day Program 
Guidance Counselor or School Psychologist

Teacher or Other School Staff Member

Social Worker or Case Manager

Religious Leader

Crisis Hotline

Support Group

Family

Friends

I searched the Internet and/or read a book

Other:

If no to (2c):

2e. If you decided to seek help for your child, who would you most likely go to for help? Select all that apply:

Psychologist, Counselor, or Therapist

Psychiatrist or Psychiatric Nurse

Primary Care Physician or Other Medical Doctor

Inpatient Hospital or Day Program

Guidance Counselor or School Psychologist

Teacher or Other School Staff Member

Social Worker or Case Manager

Religious Leader

Crisis Hotline

Support Group

Family

Friends

I would search the Internet and/or read a book

Other:

If yes to (2):

$2 \mathrm{f}$. How did you know your child was having a mental health problem?

If no to (2c), skip to (3)

If yes to $(2 c)$ :

$2 \mathrm{~g}$. How did you know that your child needed help for this problem?

2h. How did you decide where to go for help?

2i. Do you have any comments you would like to share about your experience of seeking help for this problem? 
3. Does your spouse/romantic partner have a history of mental health issues?

Yes No

If no to (3), skip to (4)

If yes to (3):

3a. What type of mental health issues? Select all that apply:

Anxiety Disorder

Depressive Disorder

ADHD

Oppositional Defiant Disorder

Autism Spectrum Disorder

Substance Use Problems

Posttraumatic Stress Disorder (PTSD)

Tic Disorder

Other:

4. Where do you normally get information about child rearing and child development? Select all that apply:

Teacher

Guidance Counselor or School Psychologist

Other School Staff Member

Pediatrician/Primary Care Physician

Other Medical Doctor

Psychologist, Counselor, or Therapist

Psychiatrist or Psychiatric Nurse

Religious Leader

Family

Friends

I search the Internet

I read books

I watch videos

Other:

Thank you for your participation in this study. If you would like a chance to win a \$25 gift certificate to Amazon.com, please enter your email address here:

Your email address will not be shared with anybody or linked to your answers. It will only be used to inform you if you win a gift certificate. 
Appendix E. Intervention Pamphlet and Follow-Up Questions

Please read through the following pamphlet and answer the questions below:

\section{What Every Parent Needs to Know to Keep Their Child On Track!}

Every child has problem behaviors - it's an important part of growing up! But sometimes it's hard to tell when a behavior becomes too much of a problem...

Here are some guidelines to help you know if your child's problem behaviors are on-track or off-track:

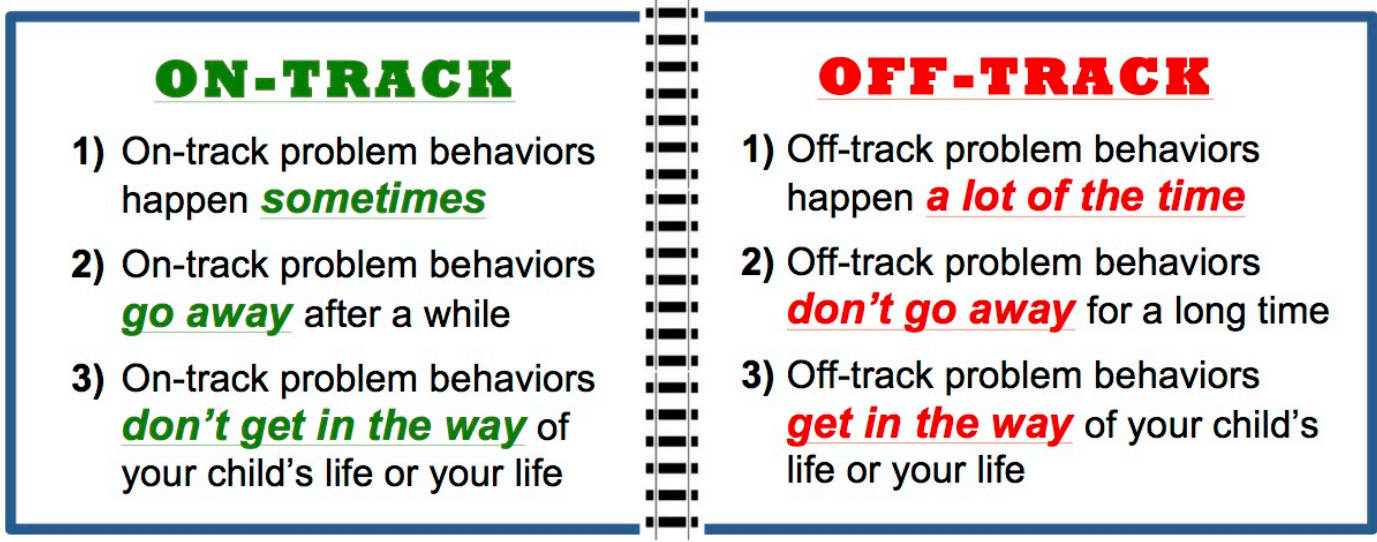

When problem behaviors get off-track, they may be a sign of a mental health issue.

If your child's problem behaviors seem off-track, you may benefit from talking to a child mental health professional for tips to help your child stay on course.

For many families, behavior therapy is the best way to get back on track. Most children who go to therapy have fun and show improvements in their behaviors, and most parents see a positive effect on the whole family!

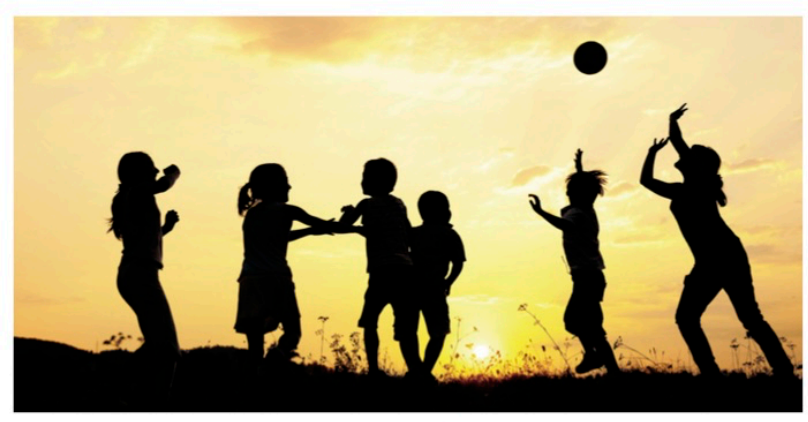

Remember - there is no harm in being cautious about your growing child, and if there is a big problem, acting early can make all the difference.

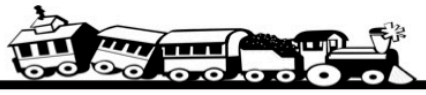


1. How helpful did you find the information in this pamphlet?

$\begin{array}{ccccc}1 & 2 & 3 & 4 & 5 \\ \text { t at all } & \text { A little } & \text { Somewhat } & \text { Very } & \text { Extremely }\end{array}$

2. How well did you understand the information in this pamphlet?

1

2

$3 \quad 4 \quad 5$

Not at all A little Somewhat Very Extremely

3. How relevant do you feel like this pamphlet is for your child?

1

2

3

4

5

Not at all A little Somewhat Very Extremely

4. Which of the following statements were made in the pamphlet?

a) Somebody else will notice your child's off-track problem behaviors

b) Off-track problem behaviors help your child make friends in school

c) Off-track problem behaviors will never get better

d) Off-track problem behaviors get in the way of your child's life or your life

5. Did the pamphlet include a phone number?

No

Yes 


\section{Bibliography}

Abera, M., Robbins, J. M., \& Fesfaye, M. (2015). Parents' perception of child and adolescent mental health problems and their choice of treatment option in southwest Ethiopia. Child and Adolescent Psychiatry and Mental Health, 9, 40, doi:10.1186/s13034-015-0072-5.

Alexandre, P. K., Martins, S. S., \& Richard, P. (2009). Disparities in adequate mental health care for past-year major depressive episodes among Caucasian and Hispanic youths. Psychiatric Services, 60, 10, 1365-1371.

Asarnow, J. R., Kolko, D. J., Miranda, J., \& Kazak, A. E. (2017). The pediatric patient-centered medical home: Innovative models for improving behavioral health. American Psychologist, 72, 1, 13-27.

Baraldi, A. N., \& Enders, C. K. (2010). An introduction to modern missing data analyses. Journal of School Psychology, 48, 1, 5-37.

Boulter, E. \& Rickwood, D. (2013). Parents' experience of seeking help for children with mental health problems. Advances in Mental Health, 11, 2, 131-142.

Brahmbhatt, K., Hilty, D. M., Hah, M., Han, J., Angkustsiri, K., \& Schweitzer, J. B. (2016). Diagnosis and treatment of attention deficit hyperactivity disorder during adolescence in the primary care setting: A concise review. Journal of Adolescent Health, 59, 135-143.

Breland, D. J., McCarty, C. A., Zhou, C., McCauley, E., Rockhill, C., Katon, W., \& Richardson, L. P. (2014). Determinants of mental health service use among depressed adolescents. General Hospital Psychiatry, 36, 296-301. 
Brestan, E. V., Eyberg, S. M., Algina, J., Johnson, S. B., \& Boggs, S. R. (2003). How annoying is it? Defining parental tolerance for child misbehavior. Child \& Family Behavior Therapy, 25, 2, 1-15.

Briggs-Gowan, M. J. \& Carter, A. S. (2008). Social-emotional screening status in early childhood predicts elementary school outcomes. Pediatrics, 121, 5, 957962.

Brown, C. M.; Girio-Herrera, E. L.; Sherman, S. N.; Kahn, R. S.; \& Copeland, K. A. (2014). Pediatricians may address barriers inadequately when referring lowincome preschool-aged children to behavioral health services. Journal of Health Care for the Poor and Underserved, 25, 406-424.

Burns, B. J.; Costello, E. J.; Angold, A. et al. (1995). Children's mental health service use across service sectors. Health Affairs, 14, 147-159.

Bussing, R.; Zima, B. T.; \& Belin, T. R. (1998). Differential access to care for children with ADHD in special education programs. Psychiatric Services, 49, 9, 1226-1229.

Bussing, R.; Zima, B. T.; Gary, F. A.; \& Garvan, C. W. (2003). Barriers to detection, help-seeking and service use for children with ADHD symptoms. The Journal of Behavioural Health Services and Research, 30, 2, 176-189.

Byrne, P. (2000). Stigma of mental illness and ways of diminishing it. Advances in Psychiatric Treatment, 6, 1, 65-72.

Cantwell, D. P., Lewinsohn, P. M., Rohde, P., \& Seeley, J. R. (1997). Correspondence between adolescent report and parent report of psychiatric diagnostic data. 
Journal of the American Academy of Child \& Adolescent Psychiatry, 36, 5, 610-619.

Centers for Disease Control and Prevention (2013). Mental health surveillance among children - United States, 2005-2011. Morbidity and Mortality Weekly Report, 62, Supplement, 1-35.

Chacko, A., Wymbs, B. T., Rajwan, E., Wymbs, F., \& Feirsen, N. (2017).

Characteristics of parents of children with ADHD who never attend, drop out, and complete behavioral parent training. Journal of Child and Family Studies, 26, 950-960.

Chambers, D., Murphy, F., \& Keeley, H. S. (2015). All of us? An exploration of the concept of mental health literacy based on young people's responses to fictional mental health vignettes. Irish Journal of Psychological Medicine, 32, $129-136$.

Chen, H., Cohen, P., \& Chen, S. (2010). How big is a big odds ratio? Interpreting the magnitudes of odds ratios in epidemiological studies. Communications in Statistics - Simulation and Computation, 39, 4, 860-864.

Clarke, J. N. (2012). Surplus suffering, mothers don't know best: Denial of mothers' reality when parenting a child with mental health issues. Journal of Child Health Care, 16, 4, 355-366.

Coffman, M. J. \& Norton, C. K. (2010). Demands of immigration, health literacy, and depression in recent Latino immigrants. Home Health Care Management and Practice, 22, 6, 116-122. 
Cohen, J. (1988). Statistical power analysis for the behavioral sciences (2nd ed.). New Jersey: Lawrence Erlbaum.

Coles, M. E., Schubert, J. R., Heimberg, R. G., \& Weiss, B. D. (2014). Disseminating treatment for anxiety disorders: Step 1: Recognizing the problem as a precursor to seeking help. Journal of Anxiety Disorders, 28, 737-740.

Collier, A. F.; Munger, M.; \& Moua, Y. K. (2012). Hmong mental health needs assessment: A community-based partnership in a small Mid-western community. American Journal of Community Psychology, 49, 73-86.

Comer, J. S. (2015). Introduction to the special series: Applying new technologies to extend the scope and accessibility of mental health care. Cognitive and Behavioral Practice, 22, 253-257.

Committee on Bioethics. (1995). Informed consent, parental permission, and assent in pediatric practice. Pediatrics, 95, 314-317.

Costello, E.; Mustillo, S.; Erkanli, A.; Keeler, G.; \& Angold, A. (2003). Prevalence and development of psychiatric disorders in childhood and adolescence. Archives of General Psychiatry, 60, 837-844.

Craven, M. A., Nikolaou, L., Allen, C. J., Crustolo, A. M., \& Kates, N. (2005). Patient education materials for mental health problems in family practice: Does location matter? Patient Education and Counseling, 56, 192-196.

Department of Health and Human Services. (2009). Code of Federal Regulations, Title 45: Public Welfare, Part 46: Protection of Human Subjects. 
De Voursney, D., \& Huang, L. N. (2016). Meeting the mental health needs of children and youth through integrated care: A systems and policy perspective. Psychological Services, 13, 1, 77-91.

Drabick, D. A. G., \& Kendall, P. C. (2011). Developmental psychopathology and the diagnosis of mental health problems among youth. Clinical Psychology, 17, 4, 272-280.

Eklund, K., Renshaw, T. L., Dowdy, E., Jimerson, S. R., Hart, S. R., Jones, C. N., \& Earhart, J. (2009). Early identification of behavioral and emotional problems in youth: Universal screening versus teacher-referral identification. The California School Psychologist, 14, 89-95.

Essex, M. J., Kraemer, H. C., Slattery, M. J., Burk, L. R., Boyce, W. T., Woodward, H. R., \& Kupfer, D. J. (2009). Screening for childhood mental health problems: Outcomes and early identification. Journal of Child Psychology and Psychiatry, 50, 5, 562-570.

Family Caregiver Alliance. (2016). Caregiver statistics: Demographics. San Francisco, CA: National Center on Caregiving. Retrieved March 18, 2017 from www.caregiver.org/print/23216

Faul, F., Erdefelder, E., Lang, A.-G., \& Buchner, A. (2007). G*Power 3: A flexible statistical power analysis program for the social, behavioral, and biomedical sciences. Behavior Research Methods, 39, 175-191.

Festinger, L. (1954). A theory of social comparison processes. Human Relations, 7, 117-140. 
Festinger, L. (1957). A theory of cognitive dissonance. Stanford, CA: Stanford University Press.

File, T. \& Ryan, C. (2014). Computer and internet use in the United States: 2013. American Community Survey Reports, ACS-28. Washington, D.C.: U.S. Census Bureau.

Ford, T.; Hamilton, H.; Meltzer, H.; \& Goodman, R. (2008). Predictors of service use for mental health problems among British schoolchildren. Child and Adolescent Mental Health, 13, 1, 32-40.

Furnmah, A., Marcus, G., \& Weis, L. (2016). Knowledge of mental illnesses: Two studies using a new test. Psychiatry Research, 244, 363-369.

Georgakakou-Koutsonikou, N., \& Williams, J. M. (2017). Children and young people's conceptualizations of depression: A systematic review and narrative meta-synthesis. Child: Care, Health, and Development, 43, 2, 161-181.

Girio-Herrera, E.; Owens, J. S.; \& Langberg, J. M. (2013). Perceived barriers to helpseeking among parents of at-risk kindergarteners in rural communities. Journal of Clinical Child and Adolescent Psychology, 42, 1, 68-77.

Glascoe, F., \& MacLean, W. (1990). How parents appraise their child's development. Family Relations, 39, 280-283.

Glascoe, F. P., \& Marks, K. P. (2011). Detecting children with developmentalbehavioral problems: The value of collaborating with parents. Psychological Test and Assessment Modeling, 53, 2, 258-279. 
Glatz, T., Stattin, H., \& Kerr, M. (2012). A test of cognitive dissonance theory to explain parents' reactions to youths' alcohol intoxication. Family Relations, 61, 629-641.

Godoy, L., \& Carter, A. S. (2013). Identifying and addressing mental health risks and problems in primary care pediatric settings: A model to promote developmental and cultural competence. American Journal of Orthopsychiatry, $83,1,73-88$.

Godoy, L.; Mian, N. D.; Eisenhower, A. S.; Carter, A. S. (2014). Pathways to service receipt: Modeling parent help-seeking for childhood mental health problems. Administration and Policy in Mental Health, 41, 4, 469-479.

Goldsmith, H. F.; Jackson, D. J.; \& Hough, R. L. (1988). Process model of seeking mental health services: Proposed framework for organizing the research literature on help-seeking. In H. Goldsmith, E. Lin, R. Bell, \& D. Jackson (Eds.), Needs assessment: Its future (Vol. DHHS Publication No. ADM 881550, pp. 49-64). Washington, D.C.: U.S. Government Printing Office.

Granello, D. H., \& Gibbs, T. A. (2016). The power of language and labels: “The mentally ill” versus "people with mental illnesses." Journal of Counseling \& Development, 94, 31-40.

Greenberg, P. E.; Sisitsky, T.; Kessler, R. C.; et al. (1999). The economic burden of anxiety disorders in the 1990s. Journal of Clinical Psychiatry, 60, 427-435.

Greenhalgh, K. T., \& Shanley, D. C. (2016). Recognising an at risk mental state for psychosis: Australian lay people and clinicians' ability to identify a problem and recommend help across vignettes. Australian Psychologist, 1-9. 
Gronholm, P. C.; Ford, T.; Roberts, R. E.; Thornicroft, G.; Laurens, K. R.; \& EvansLacko, S. (2015). Mental health service use by young people: The role of caregiver characteristics. PLoS ONE, 10, 3.

Gudiño, O. G., Lau, A. S., Yeh, M., McCabe, K. M., \& Hough, R. L. (2009). Understanding racial/ethnic disparities in youth mental health services: Do disparities vary by problem type? Journal of Emotional and Behavioral Disorders, 17, 1, 3-16.

Guo, S.; Kataoka, S. H.; Bear, L.; \& Lau, A. S. (2014). Differences in school-based referrals for mental health care: Understanding racial/ethnic disparities between Asian American and Latino youth. School Mental Health, 6, 27-39.

Hacker, K. A., Myagmarjav, E., Harris, V., Suglia, S. F., Weidner, D., \& Link, D. (2006). Mental health screening in pediatric practice: Factors related to positive screens and the contribution of parental/personal concern. Pediatrics, $118,5,1896-1906$.

Hacker, K. A., Penfold, R., Arsenault, L., Zhang, F., Murphy, M., \& Wissow, L. (2014). Screening for behavioral health issues in children enrolled in Massachusetts Medicaid. Pediatrics, 133, 1, 46-54.

Haines, M. M., McMunn, A., Nazroo, J. Y., \& Kelly, Y. J. (2002). Social and demographic predictors of parental consultation for child psychological difficulties. Journal of Public Health Medicine, 24, 4, 276-284.

Hall, C. M. \& Bierman, K. L. (2015). Technology-assisted interventions for parents of young children: Emerging practices, current research, and future directions. Early Childhood Research Quarterly, 33, 21-32. 
Harlow, L. L. (2014). The Essence of Multivariate Thinking. ( $2^{\text {nd }}$ ed.). New York: Routledge.

Harrison, A. J., Long, K. A., Manji, K. P., \& Blane, K. K. (2016). Development of a brief intervention to improve knowledge of autism and behavioral strategies among parents in Tanzania. Intellectual and Developmental Disabilities, 54, 3, 187-201.

Hay, P., Mond, J., Paxton, S., Rodgers, B., Darby, A., \& Owen, C. (2007). What are the effects of providing evidence-based information on eating disorders and their treatments? A randomized controlled trial in a symptomatic community sample. Early Intervention in Psychiatry, 1, 316-324.

Higgins, J. P. T., \& Green, S. (Eds.). (2011). Cochrane Handbook for Systematic Reviews of Interventions. [Version 5.1.0]. Retrieved February 6, 2017, from handbook.cochrane.org.

Hoetker, G. (2007). The use of logit and probit models in strategic management research: Critical issues. Strategic Management Journal, 28, 331-343.

IBM Corp. (2016). IBM SPSS Statistics for Windows, Version 24.0. Armonk, NY: IBM Corp.

Jacobs, C. O., \& Loades, M. E. (2016). An investigation into GPs' perceptions of children's mental health problems. Child and Adolescent Mental Health, 21, 2, $90-95$.

Julian, T. W., McKenry, P. C., \& McKelvey, M. W. (1994). Cultural variations in parenting: Perceptions of Caucasian, African-American, Hispanic, and AsianAmerican parents. Family Relations, 43, 1, 30-37. 
Kataoka, S.; Stein, B.; Nadeem, E.; \& Wong, M. (2007). Who gets care? Mental health service use following a school-based suicide program. Journal of the American Academy of Child and Adolescent Psychiatry, 46, 1341-1348.

Kaushik, A., Kostaki, E., \& Kyriakopoulous, M. (2016). The stigma of mental illness in children and adolescents: A systematic review. Psychiatry Research, 243, $469-494$.

Kazak, A. E., Nash, J. M., Hiroto, K., \& Kaslow, N. J. (2017). Psychologists in patient-centered medical homes (PCMHs): Roles, evidence, opportunities, and challenges. American Psychologist, 72, 1, 1-12.

Kessler, R. C.; Berglund, P.; Demler, O.; Jin, R.; Merikangas, K. R.; \& Walters, E. E. (2005). Lifetime prevalence and age-of-onset distributions of DSM-IV disorders in the National Comorbidity Survey Replication. Archives of General Psychiatry, 62, 593-602.

Khlat, M., Legleye, S., \& Sermet, C. (2014). Factors influencing report of common mental health problems among psychologically distressed adults. Community Mental Health Journal, 50, 597-603.

Kincaid, J. P., Fishburne, R. P., Rogers, R. L., \& Chissom, B. S. (1975). Derivation of new readability formulas (Automated Reading Index, Fog Count and Flesch Reading Ease Formula) for Navy enlisted personnel. Springfield, VA: National Technical Information Service (NTIS).

Kolvenbach, S., Fernández de la Crus, L., Mataix-Cols, D., Patel, N., \& Jassi, A. (2016). Perceived treatment barriers and experiences in the use of services for 
obsessive-compulsive disorder across different ethnic groups: A thematic analysis. Child and Adolescent Mental Health. doi:10.1111/camh.12197

Koot, H. \& Verhulst, F. (1992). Prediction of children's referral to mental health and special education services from earlier adjustment. Journal of Child Psychology and Psychiatry and Allied Disciplines, 33, 717-729.

Koss, J. D. (1990). Somatization and somatic complaint syndromes among Hispanics: Overview and ethnopsychological perspectives. Transcultural Psychiatry: 27, $5,5-29$.

Kutcher, S., Wei, Y., \& Coniglio, C. (2016). Mental health literacy: Past, present, and future. The Canadian Journal of Psychiatry, 61, 3, 154-158.

Kuther, T. L. (2003). Medical decision-making and minors: Issues of consent and assent. Adolescence, 38, 150, 343-358.

Lapatin, S., Gonçalves, M., Nillni, A., Chavez, L., Quinn, R. L., Green, A., \& Alegría, M. (2012). Lessons from the use of vignettes in the study of mental health service disparities. Health Services Research, 47, 3, 1345-1361.

Lau, A. S., Garland, A. F., Yeh, M., McCabe, K. M., Wood, P. A., \& Hough, R. L. (2004). Race/ethnicity and inter-informant agreement in assessing adolescent psychopathology. Journal of Emotional and Behavioral Disorders, 12, 3, 145 156.

Lawson, G. M., Nissley-Tsiopinis, J., Nahmias, A., McConaughy, S. H., \& Eiraldi, R. (2017). Do parent and teacher report of ADHD symptoms in children differ by SES and racial status? Journal of Psychopathology and Behavioral Assessment. doi:10.007/s10862-017-9591-0 
LeCroy, C. W., \& Stinson, E. L. (2004). The public's perception of social work: Is it what we think it is? Social Work, 49, 2, 164-174.

Lindsey, M. A.; Barksdale, C. L.; Lambert, S. F.; \& Ialongo, N. S. (2010). Social network influences on service use among urban, African American youth with mental health problems. Journal of Adolescent Health, 47, 367-373.

Lindsey, M. A.; Chamber, K.; Pohle, C.; Beall, P.; \& Lucksted, A. (2013). Understanding the behavioral determinants of mental health service use by urban, under-resourced black youth: Adolescent and caregiver perspectives. Journal of Child and Family Studies, 22, 107-121.

Little, R. J. A. (1992). Regression with missing X's: A review. Journal of the American Statistical Association, 87, 420, 1227-1237.

Loades, M. E., \& Mastroyannopoulou, K. (2010). Teachers' recognition of children's mental health problems. Child and Adolescent Mental Health, 15, 3, 150-156.

Lyneham, H. J., \& Rapee, R. M. (2007). Childhood anxiety in rural and urban areas: Presentation, impact and help-seeking. Australian Journal of Psychology, 59, 2, 108-118.

MacNaughton, K. \& Rodrigue, J. (2001). Predicting adherence to recommendations by parents of clinic-referred children. Journal of Consulting and Clinical Psychology, 69, 262-270.

Maniadaki, K., Sonuga-Barke, E., \& Kakouros, E. (2005). Parents' causal attributions about attention deficit/hyperactivity disorder: The effect of child and parent sex. Child: Care, Health, and Development, 31, 3, 331-340. 
Marie-Mitchell, A., Studer, K. R., \& O’Connor, T. G. (2016). How knowledge of adverse childhood experiences can help pediatricians prevent mental health problems. Families, Systems, \& Health, 34, 2, 128-135.

Marshall, J., Coulter, M. L., Gorski, P. A., \& Ewing, A. (2016). Parent recognition and responses to developmental concerns in young children. Infants \& Young Children, 29, 2, 102-115.

Meltzer, H.; Gatward, R.; Goodman, R.; \& Ford, T. (2003). Mental health of children and adolescents in Great Britan. International Review of Psychiatry, 15, 185187.

Mendenhall, A., \& Frauenholtz, S. (2015). Predictors of mental health literacy among parents of youth diagnosed with mood disorders. Child \& Family Social Work, 20, 3, 300-309.

Merikangas, K. R., Nakamura, E. F., \& Kessler, R. C. (2009). Epidemiology of mental disorders in children and adolescents. Dialogues in Clinical Neuroscience, 11, $1,7-20$.

Merikangas, K. R.; He, J. P.; Brody, D.; Fisher, P. W.; Bourdon, K.; \& Koretz, D. S. (2010). Prevalence and treatment of mental disorders among US children in the 2001-2004 NHANES. Pediatrics, 125, 75-81.

Mesman, J., \& Koot, H. M. (2001). Early preschool predictors of preadolescent internalizing and externalizing DSM-IV diagnoses. Journal of the American Academy of Child and Adolescent Psychiatry, 40, 9, 1029-36.

Molock, S. D.; Barksdale, C.; Matlin, S.; Puri, R.; Cammack, N.; \& Spann, M. (2007). Qualitative study of suicidality and help-seeking behaviors in African 
American adolescents. American Journal of Community Psychology, 40, 1-2, $52-63$.

Moses, T. (2011). Parents' conceptualization of adolescents' mental health problems: Who adopts a psychiatric perspective and does it make a difference? Community Mental Health Journal, 47, 67-81.

Nasir, A., Watanabe-Galloway, S., \& DiRenzo-Coffey, G. (2016). Health services for behavioral problems in pediatric primary care. The Journal of Behavioral Health Services \& Research, 43, 3, 396-401.

National Institute of Mental Health (2015a). Any mental illness (AMI) among U.S. adults. Retrieved March 12, 2017 from https://www.nimh.nih.gov/health/statistics/prevalence/any-mental-illness-amiamong-us-adults.shtml.

National Institute of Mental Health (2015b). Any disorder among children. Retrieved March 12, 2017 from https://www.nimh.nih.gov/health/statistics/prevalence/any-disorder-amongchildren.shtml.

Nelson, J. A., O’Brien, M., Calkins, S. D., \& Keane, S. P. (2013). Mothers' and fathers' negative responsibility attributions and perceptions of children's problem behavior. Personal Relationships, 20, 4. doi:10.1111/pere.12010.

Oh, E., \& Bayer, J. K. (2015). Parents' help-seeking processes for early childhood mental health problems. Child and Adolescent Mental Health, 20, 3, 149-154. 
Olsson, D. P., \& Kennedy, M. G. (2010). Mental health literacy among young people in a small US town: Recognition of disorders and hypothetical helping responses. Early Intervention in Psychiatry, 4, 291-298.

Patel, V.; Flisher, A. J.; Hetrick, S.; \& McGorry, P. (2007). Mental health of young people: A global public health challenge. Lancet, 369, 1302-1313.

Paulus, D. J., Wadsworth, L. P., \& Hayes-Skelton, S. A. (2015). Mental health literacy for anxiety disorders: How perceptions of symptom severity might relate to recognition of psychological distress. Journal of Public Mental Health, 14, 2, 94-106.

Pellegrini, A. D. (2011). "In the eye of the beholder": Sex bias in observations and ratings of children's aggression. Educational Researcher, 40, 6, 281-286.

Picco, L., Abdin, E., Chong, S. A., Pang, S., Vaingankar, J. A., Sagayadevan, V., et al. (2016). Beliefs about help-seeking for mental disorders: Findings from a mental health literacy study in Singapore. Psychiatric Services, 67, 1246-1253.

Pigott, T. D. (2001). A review of methods for missing data. Educational Research and Evaluation, 7, 4, 353-383.

Pihlakoski, L., Aromaa, M., Sourander, A., Rautava, P., Helenius, H., \& Sillanpää, M. (2004). Use of and need for professional help for emotional and behavioral problems among preadolescents: A prospective cohort study of 3- to 12-yearold children. Journal of the American Academy of Child \& Adolescent Psychiatry, 43, 8, 974-983.

Pihlakoski, L., Sourander, A., Aromaa, M., Rautava, P., Helenius, H., Sillanpää, M. (2006). The continuity of psychopathology from early childhood to 
preadolescence: A prospective cohort study of 3-12-year-old children. European Child and Adolescent Psychiatry, 15, 409-417.

Qualtrics (2017). Qualtrics Research Suite. Provo, UT: Qualtrics.

Quinn, P., \& Wigal, S. (2004). Perceptions of girls and ADHD: Results from a national survey. Medscape General Medicine, 6, 2, 2.

Ramsawh, H. J., Chavira, D. A., \& Stein, M. B. (2010). The burden of anxiety disorders in pediatric medical settings: Prevalence, phenomenology, and a research agenda. Archives of Pediatrics and Adolescent Medicine, 164, 10, 965-972.

Ravens-Sieberer, U.; Wille, N.; Erhard, M. et al. (2008). Prevalence of mental health problems among children and adolescents in Germany: Results of the BELLA study within the National Health Interview and Examination Survey. European Child and Adolescent Psychiatry, 17, 22-33.

Rees, C. S., Austen, T., Anderson, R. A., \& Egan, S. J. (2014). Can corrective information reduce negative appraisals of intrusive thoughts in a community sample? Behavioural and Cognitive Psychotherapy, 42, 502-507.

Reinke, W. M.; Stormont, M.; Herman, K. C.; Puri, R.; \& Goel, N. (2011). Supporting children's mental health in schools: Teacher perceptions of needs, roles, and barriers. School Psychology Quarterly, 26, 1, 1-13.

Roberts, R. E., Alegria, M., Roberts, C. R., \& Chen, I. G. (2005). Mental health problems of adolescents as reported by their caregivers: A comparison of European, African, and Latino Americans. Journal of Behavioral Health Services \& Research, 32, 1, 1-13. 
Ryan, S. M.; Form, A. J.; Toumbourou, J. W.; \& Lubman, D. I. (2015). Parent and family factors associated with service use by young people with mental health problems: A systematic review. Early Intervention in Psychiatry.

Sayal, K. (2006). Annotation: Pathways to care for children with mental health problems Journal of Child Psychology and Psychiatry, 47, 7, 649-659.

Sayal, K., Ford, T., \& Goodman, R. (2010). Trends in recognition of and service use for attention-deficit hyperactivity disorder in Britain, 1999-2004. Psychiatric Services, 61, 8, 803-810).

Sayal, K.; Mills, J.; White, K.; Merrell, C.; \& Tymms, P. (2015). Predictors of and barriers to service use for children at risk of ADHD: Longitudinal study. European Child and Adolescent Psychiatry, 24, 545-552.

Schofield, C. A., Moore, C. D., Hall, A., \& Coles, M. E. (2016). Understanding perceptions of anxiety disorders and their treatment. The Journal of Nervous and Mental Disease, 204, 2, 116-122.

Scott, S.; Knapp, M.; Henderson, J.; \& Maughan, B. (2001). Financial cost of social exclusion: Follow up study of antisocial children into adulthood. British Medical Journal, 323, 191-194.

Sebbens, J., Hassmén, Crisp, D., \& Wensley, K. (2016). Mental Health in Sport (MHS): Improving the early intervention knowledge and confidence of elite sport staff. Frontiers in Psychology, 7, 911, 1-9.

Shanley; D. C.; Reid, G. J.; \& Evans, B. (2008). How parents seek help for children with mental health problems. Administration and Policy in Mental Health, 35, $135-146$. 
Simpson, R. L. (1988). Needs of parents and families whose children have learning and behavior problems. Behavioral Disorders, 14, 1, 40-47.

Snell, T.; Knapp, M.; Healey, A.; Guglani, S.; Evans-Lacko, S.; Fernandez, J. L. et al. (2013). Economic impact of childhood psychiatric disorder on public sector services in Britain: Estimates from national survey data. Journal of Child Psychology and Psychiatry, 54, 977-985.

Sourander, A.; Santalahtis, P.; Haavisto, A.; Piha, J.; Ikaheimo, K.; \& Helenius, H. (2004). Have there been changes in children's psychiatric symptoms and mental health service use? A 10-year comparison from Finland. Journal of the American Academy of Child and Adolescent Psychiatry, 43, 1134-1145.

Sourander, A., Pihlakoski, L., Aromaa, J., Rautava, P., Helenius, H., \& Sillanpää, M. (2006). Early predictors of parent- and self-reported perceived global psychological difficulties among adolescents: A prospective cohort study from age 3 to age 15. Social Psychiatry and Psychiatric Epidemiology, 41, 173-182.

Srebnik, D.; Cauce, A. M.; \& Baydar, N. (1996) Help-seeking pathways for children and adolescents. Journal of Emotional and Behavioral Disorders, 4, 4, $210-$ 220.

Steele, L. S., Dewa, C. S., Lin, E., \& Lee, K. L. K. (2007). Education level, income level and mental health services use in Canada: Associations and policy implications. Healthcare Policy, 3, 1, 96-106.

Stein, G. L., Curry, J. F., Hersh, J., Breland-Noble, A., March, J., Silva, S. G., et al. (2010). Ethnic differences among adolescents beginning treatment for 
depression. Cultural Diversity and Ethnic Minority Psychology, 16, 2, 152158.

Taylor-Rodgers, E., \& Batterham, P. J. (2014). Evaluation of an online psychoeducation intervention to promote mental health help seeking attitudes and intentions among young adults: Randomised controlled trial. Journal of Affective Disorders, 168, 65-71.

Teagle, S. E. (2002). Parental problem recognition and child mental health service use. Mental Health Services Research, 4, 4, 257-266.

Thielke, S., Vannoy, S., \& Unützer, J. (2007). Integrating mental health and primary care. Primary Care: Clinics in Office Practice, 34, 571-592.

Thompson, V. L. S.; Bazile, A.; \& Akbar, M. (2004). African Americans' perceptions of psychotherapy and psychotherapists. Professional Psychology: Research and Practice, 35, 19-26.

Thomson, S., Marriott, M., Telford, K., Law, H., McLaughlin, J., \& Sayal, K. (2014). Adolescents with a diagnosis of anorexia nervosa: Parents' experience of recognition and deciding to seek help. Clinical Child Psychology and Psychiatry, 19, 1, 43-57.

Thurston, I. B.; Phares, V.; Coates, E. E.; \& Bogart, L. M. (2015). Child problem recognition and help-seeking intentions among black and white parents. Journal of Clinical Child and Adolescent Psychology, 44, 4, 604-615.

Tversky, A., \& Kahneman, D. (1974). Judgment under uncertainty: Heuristics and biases. Science, 185, 1124-1131. 
Umpierre, M., Meyers, L. V., Ortiz, A., Paulino A., Rodriguez, A. R., Miranda, A., et al. (2015). Understanding Latino parents' child mental health literacy: Todos a bordo/all aboard. Research on Social Work Practice, 25, 5, 607-618.

U.S. Census Bureau. (2010). Profile of general population and housing characteristics: 2010 demographic profile data. Retrieved March 12, 2017 from https://factfinder.census.gov/faces/tableservices/jsf/pages/productview. $\mathrm{xhtml}$ ?src $=\mathrm{CF}$

U.S. Census Bureau. (n.d.). Educational attainment: 2011-2015 American Community Survey 5-year estimates. Retrieved March 18, 2017 from https://factfinder.census.gov/rest/dnldController/deliver?_ts=507902367989

U.S. National Telecommunications \& Information Administration. (2010). Exploring the digital nation: Home broadband Internet adoption in the United States. Retrieved March 17, 2017 from https://www.ntia.doc.gov/files/ntia/publications/esa_ntia_us_broadband_adopti on_report_11082010_1.pdf

Verhulst, F. C. \& Van Der Ende, M. S. (1997). Factors associated with child mental health service use in the community. Journal of the American Academy of Child and Adolescent Psychiatry, 36, 901-909.

Visser, S. N., Zablotsky, B., Holbrook, J. R., Danielson, M. L., \& Bitsko, R. H. (2015). Diagnostic experiences of children with attention-deficit/hyperactivity disorder. National Health Statistics Reports, 81, 1-7.

Waddell, C.; Offord, D. R.; Shepherd, C. A.; Hua, J. M.; \& McEwan, K. (2002). Child psychiatric epidemiology and Canadian public policy-making: The state of the 
science and the art of the possible. Canadian Journal of Psychiatry, 47, 825832.

Wang, P. S.; Berglund, P.; Olfson, M.; Pincus, H. A.; Wells, K. B.; \& Kessler, R. C. (2005). Failure and delay in initial treatment contact after first onset of mental disorders in the National Comorbidity Survey replication. Archives of General Psychiatry, 62, 603-613.

Waters, J. (2015). Snowball sampling: A cautionary tale involving a study of older drug users. International Journal of Social Research Methodology: Theory \& Practice, 18, 4, 367-380.

Willinger, U., Schaunig, I., Jantscher, S., Schmoeger, M., Loader, B., Kummer, C., \& Peer, E. (2011). Mothers' estimates of their preschool children and parenting stress. Psychological Test and Assessment Modeling, 53, 2, 228-240.

Woodman, A. C., \& Hauser-Cram, P. (2013). The role of coping strategies in predicting change in parenting efficacy and depressive symptoms among mothers of adolescents with developmental disabilities. Journal of Intellectual Disability Research, 57, 6, 513-530.

Yen, C. F., Chen, C. C., Lee, Y., Tang, T. C., Ko, C. H., \& Yen, J. Y. (2005). Insight and correlates among outpatients with depressive disorders. Comprehensive Psychiatry, 46, 5, 384-389.

Youngstrom, E. A., Loeber, R., \& Stouthamer-Loeber, M. (2000). Patterns and correlates of agreement between parent, teacher, and male adolescent ratings of externalizing and internalizing problems. Journal of Consulting and Clinical Psychology, 68, 6, 1038-1050. 
Zwaanswijk, M., Verhaak, P. F. M., Bensing, J. M., van der Ende, J., \& Verhulst, F. C. (2003). Help seeking for emotional and behavioural problems in children and adolescents: A review of recent literature. European Child and Adolescent Psychiatry, 12, 153-161.

Zwaanswijk, M., Verhaak, P. F.M., van der Ende, J., Bensing, J. M., \& Verhulst, F. C. (2006). Change in children's emotional and behavioural problems over a oneyear period: Associations with parental problem recognition and service use. European Child and Adolescent Psychiatry, 15, 127-131. 